\title{
Seismic Fragility And Post-Earthquake Reparability of Concrete Frame With Low-Bond High-Strength Rebar Reinforced Concrete Column
}

Junhua Wang ( $\nabla$ wangjunhua19870527@163.com )

Shenzhen University https://orcid.org/0000-0003-4101-6837

\section{Y.P. Sun}

Kobe University: Kobe Daigaku

\section{Research Article}

Keywords: seismic fragility, post-earthquake reparability, LBHSR, IDA, residual deformation

Posted Date: August 20th, 2021

DOl: https://doi.org/10.21203/rs.3.rs-809408/v1

License: (c) (1) This work is licensed under a Creative Commons Attribution 4.0 International License. Read Full License

Version of Record: A version of this preprint was published at Structures on March 1st, 2022. See the published version at https://doi.org/10.1016/j.istruc.2022.01.001. 
1 Seismic Fragility and Post-Earthquake Reparability of Concrete Frame with Low-Bond High-Strength Rebar Reinforced Concrete Column

$8{ }^{\mathrm{b}}$ Department of Architecture, Graduate School of Engineering, Kobe University, Kobe, 657-8501, Japan.

11 *Corresponding authors at Guangdong Provincial Key Laboratory of Durability for Marine Civil 12 Engineering, College of Civil and Transportation Engineering, Shenzhen University, Shenzhen, 518000, 13 China (J.H. Wang), E-mail: wangjunhua@szu.edu.cn; Department of Architecture, Graduate School of 14 Engineering, Kobe University, Kobe, 657-8501, Japan (Y.P. Sun), E-mail: sun@ person.kobe-u.ac.jp 15 16 


\section{Seismic Fragility and Post-Earthquake Reparability of Concrete Frame with Low-Bond High-Strength Rebar Reinforced Concrete Column}

\section{Abstract}

To further study the global seismic behaviour and post-earthquake reparability of RC building frames with the proposed self-centring columns with low-bond high-strength reinforcements (LBHSRs), incremental dynamic analysis (IDA) of five-floor and ten-floor frame archetypes under excitation by twenty ground motions (GMs) was performed. First, the pushover results indicated that the use of LBHSR could substantially improve the yield and ultimate lateral drift of both the archetypes, although the archetype had a smaller longitudinal reinforcement ratio (LR) of the LBHSR and similar seismic resistance. The dynamic response results indicated that the archetype with LBHSRs exhibited a smaller residual story lateral drift although the effectiveness of the use of LBHSR to reduce seismic response was not apparent for the archetype subjected to a low-intensity earthquake. The seismic fragility results showed that LBHSR was more effective for preventing seismic collapse than for attaining the immediate occupancy (IO), life safety (LS), and collapse prevention (CP) limit states. Furthermore, the higher the LR, the lower was the likelihood of seismic collapse. The fragility curves of the residual story lateral drifts indicate that the use of LBHSR can significantly mitigate the residual deformation in the DS1, DS2, and DS3 damage states. Moreover, the effectiveness increases with the increase in the LR and earthquake intensity. Comparisons of residual story lateral drifts between the predicted results and IDA results indicated that the present calculation models are not suitable for predicting residual deformation. The model needs to be studied further.

Keywords: seismic fragility; post-earthquake reparability, LBHSR, IDA, residual deformation. 
41 As is well-established, earthquakes are one of the major natural disasters encountered by humans. The

42 severe earthquakes of recent decades have caused substantial human casualties and socio-economic losses.

43 Furthermore, the indirect severe damage caused by an earthquake to the local politics, economy, human 44 psychology, and social development are considerable (Wang and Zhao 2018). Earthquake-resistant 45 structural engineering has been developing over many generations. The countries highly vulnerable to 46 earthquakes have proposed many performance-based design methods of engineering structures, e.g., the 47 three-level seismic design method proposed in the Chinese code (GB50011-2010, 2010) and two-stage 48 seismic design method proposed in the Japanese code (AIJ, 2016).

49 The design concept for preventing engineering structures from collapsing to protect human lives is 50 effective. Human casualties in the recent earthquakes in Japan were significantly less than those in earlier 51 earthquakes. However, these design methods result in significant seismic damage of engineering 52 structures in the form of plastic hinge. Engineering structures that sustain severe seismic damage incur 53 substantial post-earthquake repair expense. Occasionally, a structure that does not undergo seismic 54 collapse needs to be demolished because of the substantial repair cost. This substantially hinders the 55 rehabilitation of society and human life because the repair of infrastructure including buildings and 56 bridges is highly time-consuming and requires substantial socio-economic resources. Therefore, scholars 57 have indicated that engineering structures should satisfy the traditional design objective of ensuring 58 human safety as well as limit the seismic damage and residual deformation to aid the repair of the 59 structure after an earthquake (Kawashima 1997). Furthermore, the residual deformation after an 60 earthquake also poses a risk to structural safety during post-earthquake fires (Wang et al. 2020). 61 "Resilient City" should become the next research emphasis for seismic-resistant engineering structures.

62 Since 1963, Housner (1963) determined that structures did not sustain severe seismic damages in the 631960 Chile earthquake because the connection between the main structure and foundation had been 
64 weakened. Since the completion of his theoretical analysis of the working mechanism of rocking

65 structures, the design principle of weakening the connection of a structure to reduce the overall structural 66 seismic damage has been receiving increasing attention of scholars worldwide. Since the 1990s, 67 American and Japanese scholars have carried out substantial research on the seismic performance of 68 rocking structures. To control the rocking amplitude of a rocking structure, the post-tensioned (PT) pre69 stressing technique was used to provide the self-centring force for the structure. This type of rocking 70 structure is called self-centring (SC) structure. The research on SC structures has focused mainly on 71 precast reinforced concrete (RC) shear walls and RC frames. Prof. Richard Sause of Lehigh University 72 and Prof. Yahya C. Kurama of the University of Notre Dame carried out extensive and comprehensive 73 works. Their early test results demonstrated that the residual displacement and seismic damage of an SC 74 shear wall structure are marginal and that the force-displacement curve exhibits a flag-shape, which 75 reveals a strong self-reset capability. However, its energy dissipation capacity is low (Kurama et al. 1999). 76 The energy dissipation capacity could be improved significantly by additional dampers. The simulation 77 analysis showed that the application of rocking or SC structural elements was favourable to the seismic 78 resistance of an entire structure (Zibaei and Mokari 2014; Kurama and Shen 2008). Based on this 79 consideration, Panian et al. (2008) have used SC shear walls in the construction of David Brower Center. 80 Priestley et al. (1996) attempted to use partially debonded post-tensioned prestressed steel bars in precast 81 reinforced-concrete beam-column joints to improve seismic performance.

82 Kawashima et al. (1997) comprehensively investigated the residual deformation of single-degree-of83 freedom (SDOF) structures. It was observed that the residual deformation of structures is controlled 84 mainly by the ductility ratio, post-yield stiffness, and yield stiffness ratio. Priestley and Christopoulos et 85 al. (Christopoulos et al. 2003; Pampanin et al. 2008) theoretically analysed the residual deformation of 86 SDOF and multi-degree-of-freedom (MDOF) structures. According to the study results of Kawashima 87 and Priestley et al., a series of formulas were proposed in the Seismic Design Code for Bridge 
88 Engineering of Japan (JRA 2017) and American FEMA specification (FEMA 2012).

89 Meanwhile, although rocking and SC structures have been developed for nearly 30 years, these have 90 not been applied extensively in practical engineering. Certain problems prevent its popularisation and 91 development: 1) Economic cost (MacRae 2013; Roke et al. 2013). The PT technique increases the 92 difficulty of structural design. In addition, the anchorage construction of pre-stressing bars in shear walls 93 and frames is difficult. These increase the construction cost. However, owing to the uncertainty of 94 earthquake, the economic advantages afforded by the high seismic performance of rocking and SC 95 structures in the life cycle may be offset by the increased cost involved in the preliminary design and 96 construction of the structure. This substantially reduces the willingness of residents to apply it. 2) Design 97 difficulty. As mentioned earlier, the working mechanism of rocking and SC structures differs from those 98 of traditional structures. This implies that a new design method is required, which increases the design 99 challenge for engineers. 3) Inherent deficiency of the PT technique (Wang and Zhao 2018). Loss of pre100 stress occurs in the life cycle of SC structures. It is difficult to evaluate the influence of pre-stressing loss 101 on the seismic performance of SC structures. Consequently, it is worthwhile to develop SC structures 102 with simple and inexpensive technology (Wang and Zhao 2018).

103 The authors have theoretically analysed the influence of the bond strength of longitudinal 104 reinforcement on the seismic behaviours of RC columns. The results indicated that a decrease in the bond 105 strength can substantially improve the ductility of RC columns and that the yield process can be delayed 106 such that the longitudinal reinforcement can be maintained in the elastic region (Wang and Sun 2020a; 107 Wang and Sun 2020b). Based on the above theoretical foundation, the authors proposed the use of low108 bond high-strength reinforcement (LBHSR) as the tensile longitudinal rebar of RC columns.

109 Certain experimental programs were conducted by the authors to investigate the seismic behaviours of 110 the proposed RC columns. The details of the structural forms of the proposed test RC columns with 111 LBHSRs are shown Fig.1. As is evident from the figure, the structural forms of the proposed RC columns 
112 are identical to those of conventional RC columns. This substantially reduces the difficulties of design

113 and construction and further reduces the cost of this new type of SC building structures.

114 The low-bond property of longitudinal rebars can be realized by two methods: 1) use partially 115 debonded normal high-strength twisted reinforcement (PDHSR) (see Fig.1 (a)); and 2) use low-bond116 strength high-strength reinforcement (LBSHSR) (see Fig.1 (b)). PDHSR can be realized by wrapping the 117 surface of high-bond high-strength reinforcement (HBHSR) with a poly vinyl chloride (PVC) sleeve or 118 steel tube, as shown in Fig.1 (a). A type of LBSHSR is shown in Fig.2. This type of high-strength 119 reinforcement (called SBPDN 1423/1275 (hereinafter referred to as SBPDN) rebar) was developed by a 120 Japanese steel company in the 1950s. Thereafter, it was gradually adopted in the civil engineering field. 121 For example, it has been used in the construction of the high-speed railway of China and is used as 122 transverse reinforcement in Japan. The types of LBSHSR with different bond strengths have been 123 standardized (GB/T 5223.3-2017), as shown in Fig.2. The surface of an SBPDN rebar displays ribs 124 (similar to USD 685 rebar) rather than spiral grooves. According to the test results of Funato et al. (2013), the bond strength of an SBPDN rebar was a fifth of that of conventional high-strength USD 685 rebars with ribs.

127 A tie plate is required to prevent bond-slip at the middle and both ends of RC columns with LBSHSRs. 128 The longitudinal reinforcement can be anchored by the tie plates at both top and bottom of the column or 129 through $90-180^{\circ}$ hooks. The debonded length and bond strength can be freely selected by the designer 130 according to the demands of structural performance. To further reduce the seismic damage and prevent 131 premature shear failure of an RC column, the column section can be confined by a fibre polymer plastic 132 (FRP) jacket and steel tube (ST), as shown in Fig.1. Further details of the proposed RC columns with 133 LBHSRs are available in the companion papers (Wang et al. 2019; Wang et al. 2020). The experimental 134 results indicated that the RC columns with LBHSRs displayed strong SC capacity. In addition, the 135 residual deformation after seismic loading was smaller compared with that of RC columns with normal 
136 bond-strength reinforcements. Furthermore, the seismic damage of the proposed RC columns was marginal (see Fig.3). This further reduced the difficulty and cost of post-earthquake repair.

138 The seismic behaviours of beam-column joint assembly reinforced by either PDHSRs or normal steel rebars were experimentally investigated (Wang 2021). The results indicated that the use of PDHSR in the 140 columns was favourable to the improvement of the ductility of beam-column joints. Meanwhile, the use 141 of both beams and columns with PDHSRs can substantially improve the seismic behaviours of beam142 column joints, including their seismic resistance, ductility, and residual deformation. This prevents the 143 deterioration of the seismic behaviours of the RC frame with the proposed columns because of the use of 144 PDHSR.

145 The seismic behaviours of RC columns with LBSHSRs or PDHSRs subjected to lateral cyclic loading 146 have been investigated extensively and comprehensively through experiment and evaluation (Wang et al. 147 2019; Wang et al. 2020; Wang et al. 2021). Further study is required to better comprehend the influence 148 of the proposed SC columns with LBHSRs on the seismic responses of an entire RC frame. This paper 149 presents the time-history analysis results of five-floor and ten-floor building frame archetypes with 150 concrete columns reinforced by steel rebars with different bond properties. Nonlinear numerical models 151 considering steel-bond slip were proposed in OpenSees (2018), and incremental dynamic analysis (IDA) 152 was performed to obtain seismic responses of the designed building frame archetypes based on twenty 153 earthquake ground motions. The results were used to determine 1) seismic fragility curves for evaluating 154 seismic collapse 2) and residual drift curves for estimating the post-earthquake reparability of the 155 designed building archetypes. Furthermore, the residual story lateral drifts obtained from the IDA were 156 evaluated using the equations proposed in the FEMA and JRA codes. The works of this study provide a 157 better understanding of the proposed RC column application for designing an inexpensive SC-RC frame 158 by using simple techniques. 


\subsection{Design of building frame archetypes}

Five-floor and ten-floor $\mathrm{RC}$ building frames were designed to represent the expected design variation of short and medium-rise buildings. Fig. 4 shows the plan view and elevation of the building frames. Each floor contains many moment resisting frames (MRFs) in both horizontal and vertical directions. There are 165 four and seven bays in the vertical and horizontal directions, respectively. It is assumed that the building 166 frames has identical story height and bay width of $3.2 \mathrm{~m}$ and $4.0 \mathrm{~m}$, respectively. The intermediate MRF was selected to perform the time-history analysis. The columns of the first floor were assumed to fix the foundation. It was assumed that the width of the slabs was $4.0 \mathrm{~m}$, and the membrane element was used to model the slabs. Live loads of $2.0 \mathrm{kN} / \mathrm{m}^{2}$ were assigned to all the building floors. The dead load was calculated according to the self-weights of all the members including the columns, beams, and slabs.

The building archetypes were assumed to be located in Dongchuan District, Kunming City, Yunnan Province of China. It is in the southwestern of China and is one of the areas that are highly vulnerable to earthquake. The latitudes and longitudes are $102^{\circ} 47^{\prime}-103^{\circ} 18^{\prime}$ and $25^{\circ} 57^{\prime}-26^{\circ} 32^{\prime}$, respectively. According to the seismic design code of China (GB 50011-2010), the building archetypes satisfy the Seismic design category (SDC) 9, which is the highest seismic vulnerability. The maximum considered earthquake (MCE) spectral acceleration Sa was $0.4 \mathrm{~g}$. The soil was assumed to be of Class II. The natural eigenperiod $\mathrm{T}_{\mathrm{g}}$ is $0.55 \mathrm{~s}$. The first modes of the building archetypes were considered in the nonlinear time-history analysis. The fundamental periods $\mathrm{T}_{1}$ of the five-floor and ten-floor archetypes were $0.5 \mathrm{~s}$ and $1.0 \mathrm{~s}$, respectively. These were calculated by Eq. (1) proposed in the ASCE 7 code (ASCE/SEI 7-10, 180 2010):

$$
T_{1}=0.1 N
$$

182 where $T_{1}=$ fundamental period and $N=$ number of stories of the building frame archetype. 
The seismic design results are shown in Table 1. The design earthquake accelerations of the building 185 archetypes were calculated from their fundamental periods using the equations for calculating earthquake acceleration proposed in the seismic design code of China (GB 50011-2010).

187 The compressive strength of the concrete was assumed to be $36.0 \mathrm{MPa}$, and the confinement ratio of 188 the column section was assumed to be 1.22 . Meanwhile, the beam section did not consider the 189 confinement to concrete. The dimensions of the column and beam are shown in Fig.4 (b). The columns 190 had a square cross-section with dimensions of $500 \times 500 \mathrm{~mm}$. Meanwhile, the size of the beam section 191 was $400 \times 450 \mathrm{~mm}$. Twelve longitudinal rebars with a diameter of $25 \mathrm{~mm}$ were assigned to the beam sections to yield a longitudinal rebar ratio of $3.27 \%$. The yield strength of the longitudinal reinforcement used in the beams was assumed to be $454 \mathrm{MPa}$.

Table 1 shows the basic information of the designed column longitudinal reinforcement. Two types of longitudinal reinforcements were used in the columns: yield strength of $500 \mathrm{MPa}$ to represent high-bond normal-strength reinforcement (HBNSR), yield strength of $942 \mathrm{MPa}$ with a debonding length of $960 \mathrm{~mm}$ (60\% of the shear span of the column), or bond strength of 3.0 MPa to represent LBHSR. Sixteen HBNSRs or LBHSRs with a diameter of $25 \mathrm{~mm}$ was designed to reinforce the column section to yield a longitudinal reinforcement ratio (LR) of 3.14\%. However, owing to the higher yield strength of LBHSR, the seismic base force resistances of the building archetypes with LBHSRs was higher than those for the archetypes with HBNSRs with identical LR (see Fig.10). To eliminate the effect of the yield strength of LBHSR and further study the influence of the bond property of longitudinal reinforcement on the seismic responses of building archetypes, 12 D22 and 4 D12 LBHSRs (to yield a lower LR of 2.09\%) was assumed to reinforce the columns of another building archetype scenario for providing a seismic base force resistance similar to that of the building archetype scenario with 16 D25 HBNSRs (see Table 1). The damping ratio of both the archetypes was assumed to be $5.0 \%$. 


\subsection{Ground motions}

209 Twenty ground motions (GMs) including ten far-field (FF), five near-field pulse (NFP), and five near-

210 field no-pulse (NFNP) GMs summarized by FEMA P695 (FEMA 2009) were selected to perform the 211 nonlinear time-history analysis. The acceleration data of these GMs were downloaded from 'PEER 212 Strong Ground Motion Database'. The basic information including locations, years, magnitude, peak 213 ground acceleration (PGA), and duration are shown in Table 2. The corresponding acceleration spectral 214 with a damping ratio of 5.0\% is shown in Fig.5. The Chinese seismic design code (GB 50011-2010) 215 includes four SDCs: Classes 6, 7, 8, and 9. The curve of the average value of all the selected GMs and the 216 design earthquake acceleration spectral of the four SDCs are compared in Fig.5. As is evident from the 217 figure, the maximum earthquake acceleration of the average curve is between the curves of SDCs 7 and 8. 218 Furthermore, the curve is close to the SDC 8 curve when the period is larger than $\mathrm{T}_{\mathrm{g}}(=0.55 \mathrm{~s})$.

\subsection{Nonlinear finite element model}

The two-dimensional OpenSees element model of the MRF is shown in Fig.6. The beam and column were simulated by the NonlinearBeamColumn element. Fiber-Section was used to simulate the beam and column sections. The playout and mechanical properties of the longitudinal reinforcements were identical to those of the design illustrated in Fig. 4 (b). The concrete and steel models were UniaxialMaterial Concrete 02 with linear tension softening and Steel 02 (Giuffré-Menegotto-Pinto model) with isotropic strain hardening, respectively. A zeroLength shear spring element was used to simulate the shear behaviour of the beam-column joint (Alath and Kunnath 1995) (see Fig.6). Meanwhile, the steel-bond slip was simulated through the simplified elastic modulus of longitudinal rebars of beam and column. The mechanical property of the shear spring was calculated by the Pinching 4 material model. The model of shear strength versus shear strain proposed by Kim and LaFave (Kim et al. 2008; Kim et al. 2009; Kim and LaFave 2007) was used to determine the parameters of the Pinching 4 material model. 


\subsection{Considerations of column sectional confinement and steel-bond slip of LBHSR}

The confined concrete compressive strength was used to simulate the FRP-confined column section.

The confinement ratio was calculated using Eq. (2) of the model proposed by Lam and Teng (2003).

Meanwhile, Eq. (3) proposed by Sun and Sakino (1996) was used to calculate the confinement ratio

owing to ST. It was verified that the above two material models could be used to reasonably simulate the confinement effect of FRP and ST on the test column sections (Wang et al. 2019; Wang et al. 2021).

$$
\begin{aligned}
& K=\frac{f_{c c}}{f_{c 0}}=1+3.3 \frac{f_{l}}{f_{c 0}} ; \quad f_{l}=\frac{2 f_{f r p} t}{d} \\
& K=1+4.1\left(\frac{2}{D_{t} / t_{s}-2}\right) \cdot \frac{f_{y t}}{f_{c 0}}
\end{aligned}
$$

where $K=$ confinement ratio of concrete, $f_{c c}=$ confined concrete strength, $f_{c 0}=$ unconfined concrete 242 strength, $f_{l}=$ confining pressure owing to FRP, $f_{f r p}=$ tensile strength of FRP, $t=$ total thickness of FRP, $t_{s}$ $243=$ thickness of ST, and $d=$ diameter of confined concrete. $D_{t}$ is the diameter of the section considering the 244 thickness of the steel tube, and $f_{y t}$ is the yield strength of the hoops and steel tubes.

The authors used a modified Young's modulus of steel for the simulation to estimate the steel-bond slip of the LBHSR of the columns. The applicability of this method has been validated (Wang et al. 2019; Wang et al. 2021). The calculation model of the steel-bond slip of LBHSR is shown in Fig.7. As is evident, the steel-bond slip for PDHSR contains two parts: one is from the debonding region, and the other is caused by the bond region of the longitudinal reinforcement. Meanwhile, the steel-bond slip for LBSHSR is caused only by the bond region. The calculation of the steel-bond slip of longitudinal reinforcement with different bond strengths was based on the equations proposed by Sezen et al. (Sezen and Selzler 2008; Sezen and Chowdhury 2009; Lodhi and Sezen 2012). According to the anchorage 254 length of the longitudinal reinforcement, two scenarios were considered (see Fig.7). Scenario (a): the 
anchorage length is adequate. Scenario (b): the development length of the yield longitudinal reinforcement $l_{d y}$ exceeds the anchorage length $L_{e m d}$. For simplicity, unified equations are proposed for 257 estimating the steel-bond slip:

$$
\begin{aligned}
& E_{s m}= \begin{cases}\frac{4 u E_{s} L_{e m d}}{4 u L_{e m d}+4 u l_{p d}+f_{y} d_{b}} ; & \text { Scenario } a \\
\frac{f_{y}}{\varepsilon_{y}+0.5\left(\varepsilon_{e}+\varepsilon_{y}\right)\left(1-\frac{l_{p d}}{L_{e m d}}\right)} ; & \text { Scenario } b\end{cases} \\
& \varepsilon_{e}=\varepsilon_{y}+\frac{4 u\left(L_{e m d}-l_{p d}\right)}{f_{y} d_{b}}
\end{aligned}
$$

where $d_{b}=$ diameter of reinforcing bar, $\varepsilon_{e}=$ axial strain at the end of longitudinal rebar, $\varepsilon_{y}=$ axial yield strain of reinforcing bar, $f_{y}=$ yield stress of reinforcing bar, and $u=$ bond strength between concrete and 263 longitudinal rebar. $L_{e m d}=$ embedment length of longitudinal rebar, $E_{s m}=$ modified Young's modulus of 264 steel, $E_{s}=$ Young's modulus of steel, and $l_{p d}=$ debonding length of steel rebar.

\subsection{Validation of numerical model}

To validate the applicability of the above OpenSees models, the same OpenSees element model was used to simulate the experimental seismic responses of the columns with normal high-strength reinforcements and LBHSRs tested by the authors (Wang et al. 2019; Wang et al. 2021). The calculation of the confinement of FRP and ST and the simulation of steel-bond slip shown in Eqs. (2)-(5) were also used in the simulations of test columns. The OpenSees models for cantilever and double-curvature beamcolumns are shown in Fig.8. The comparisons of the predicted and experimentally determined seismic responses of the test columns are shown in Fig.9. As is evident from the figure, the proposed OpenSees 274 element models shown in Fig.8 can be used to predict the seismic behaviours (including the stiffness, 275 seismic resistance, ductility, and residual lateral drift) of test columns reinforced by longitudinal 
reinforcements (PDHSRs, LBSHSRs, HBHSRs) with good accuracy. As indicated, the experimentally

277 determined early stiffness in the negative direction of the specimen columns PPD0, PPD4, and PPD6

278 differed marginally from the predicted results. This was attributed to the seismic damage in the negative

279 direction initiated when the test column was thrust in the positive direction. It should be noted that the 280 experimentally determined seismic behaviours of the test columns FATSB and FATUS in the negative 281 direction did not agree with the predicted results. This was attributed to the fact that the capacity of the 282 hydraulic jack during the testing was smaller than the seismic resistance capacity of these two test 283 columns. The maximum lateral drift cycles were up to $3.5 \%$ and $2.0 \%$ for FATSB and FATUS, 284 respectively (Wang et al. 2021).

\section{Static pushover analysis}

An inverted triangular load pattern following the Chinese seismic design code GB 50011-2010 (2010) was used in the pushover analysis. The comparisons of the pushover results of the archetypes with HBNSRs and LBHSRs are shown in Fig. 10. It is evident from the figure that both five-archetype and 10archetype with an identical LR $(=3.14 \%)$ of LBHSRs displayed better seismic responses (including higher seismic resistance and higher deformability) compared with the archetypes with HBNSRs. The lateral drifts at the peak lateral forces of the two archetypes with LBHSRs were $180 \%$ and $241 \%$, respectively, higher than those of the archetypes with HBNSRs. When the LR of LBHSRs was decreased from $3.14 \%$ to $2.09 \%$, the seismic base shear forces of the building archetypes were similar to those of the archetype reinforced with HBNSRs having an LR of 3.14\%. However, the peak lateral drifts of the fivefloor and ten-floor archetypes with LBHSRs were increased by $139 \%$ and $222 \%$, respectively, compared with the archetypes with HBNSRs. For the two LRs of LBHSR (3.14\% and 2.09\%), both the archetypes had reduced stiffness compared with that for HBNSRs $(\mathrm{LR}=3.14 \%)$ from a certain lateral drift level, moreover, lower the LR, lower was the stiffness (see Fig.10). These observation were consistent with the 
experimental results shown in the references (Wang et al. 2019; Wang et al. 2021). This can be attributed

301 to the fact that the low-bond property of LBHSR delayed the development of the yielding process of the 302 longitudinal reinforcement. Thereby, the archetypes with LBHSRs had larger yield roof lateral drifts, $R_{y, \text { eff }}$ 303 (see Table 1). When the LR of LBHSR was $3.14 \%$, the $R_{y, \text { eff }}$ of the archetypes with LBHSRs was 2.81 and 3041.88 times, respectively, that of the archetypes with HBNSRs. Meanwhile, because the LR was $2.09 \%$, 305 the $R_{y, \text { eff }}$ values were still increased by $48.6 \%$ and $3.3 \%$, respectively, for the five-floor and ten-floor 306 archetypes.

307 The over-strength factor $\Omega$ and period-based ductility $\mu_{T}$ were used to quantify the seismic behaviour of 308 the building frame archetypes (see Table 1). The average yield displacement of the calculated results of 309 three methods including first yield, the geometric graphic method, and the equivalent elastoplastic energy 310 method defined by Park (1989) was used in this study to calculate the period-based ductility. Meanwhile, 311 the point of $20 \%$ strength loss $(0.8 \mathrm{~V})$ was considered as the ultimate displacement. As shown in Table 1 , 312 the $\Omega$ s of both five-floor and ten-floor archetypes were similar when the LRs of HBNSR and LBHSR 313 were $3.14 \%$ and $2.09 \%$, respectively. Consequently, the use of LBHSR can reduce the amount of 314 longitudinal reinforcement. However, when the LR of LBHSR was $3.14 \%$, the $\Omega$ s were larger by $31 \%$ 315 and $16 \%$, respectively, compared with the archetypes with HBNSRs. As shown in Table 1, the $\mu_{T}$ of the

316 five-floor archetypes with LBHSRs was marginally smaller compared with that attained with HBNSRs.

317 Meanwhile, the ten-floor archetypes with LBHSRs had larger $\mu_{T}$ compared with the ten-floor archetypes 318 with HBNSRs.

\section{Dynamic response and seismic fragility evaluation}

Fig.11 shows the dynamic responses including the history-time responses of the maximum story lateral drifts and hysteretic behaviours of the five-floor archetypes with HBNSRs and LBHSRs subjected to GM 12 and GM13. The amplitude-scaling factors (CFs) of GM 12 and GM 13 were 1.0. As is evident from 
324 Fig.11 (a), the maximum story lateral drift of the archetype with HBNSRs (LR $=3.14 \%$ ) subjected to GM 32512 was approximately $2.0 \%$, whereas the value for the archetype with LBHSRs was higher than $2.0 \%$ for 326 LRs of $3.14 \%$ and $2.09 \%$. However, for the high-intensity earthquake GM 13, the maximum story lateral 327 drift of the archetype with HBNSRs ( $\mathrm{LR}=3.14 \%)$ was approximately $10.0 \%$. It could be assumed to be a 328 collapse. However, the values of the archetypes with LBHSRs were decreased to $6.42 \%$ and $8.23 \%$ for 329 LRs of $3.14 \%$ and $2.09 \%$, respectively. As shown in Fig.11 (b), when subjected to GM12, the base shear 330 force of the archetype with LBHSRs was smaller than that of the archetype with HBNSRs. For GM 13, 331 the archetype with LBHSRs having an LR of 3.14\% displayed larger base shear force, whereas the base 332 shear forces of the archetypes with HBNSRs having an LR of 3.14\% and those with LBHSRs having an 333 LR of $2.09 \%$ were equal. Furthermore, the stiffness of the archetype with LBHSRs was also smaller than 334 that of the archetype with HBNSRs when the lateral drift entered the large deformation stage. These 335 observations were in agreement with the static pushover results shown in Fig.10. It was also observed that 336 the residual lateral drifts of the archetypes with three longitudinal reinforcement scenarios were similar 337 when subjected to GM12. Meanwhile, the archetypes with LBHSRs having LRs of 3.14\% and 2.09\% 338 displayed smaller residual lateral drifts compared with the archetypes with HBNSRs $($ LR $=3.14 \%)$ 339 subjected to GM13. Furthermore, larger the LR of LBHSR, smaller was the residual lateral drift (see 340 Fig.11(a)). The dynamic responses shown in Fig.11 indicate that the only apparent effect of the use of 341 LBHSR is the reduction in the seismic dynamic responses of structures subjected to a high-intensity 342 earthquake.

343 The lateral drift responses in conjunction with the height of the archetype are shown in Fig.12. 344 Identical to the observations in Fig.11, the maximum story lateral drift response of the archetype 345 subjected to the relatively moderate or low-intensity earthquake G12 was significantly smaller compared 346 with that for GM 13. However, regardless of the earthquake intensity, LBHSR was remarkably effective 347 in reducing the residual story lateral drift, as shown in Fig.12 (b). Similar conclusions were obtained from 
comparisons of the dynamic responses of the ten-floor archetypes reinforced by LBHSRs and HBNSRs.

349 IDA was performed to capture the entire seismic response of the designed building frame archetype.

350 The time-history analysis was conducted repeatedly through amplitude-scaling of each GM until the 351 archetypes were assumed as the failure. The time-history analysis was terminated when the inter-story 352 drift ratio exceeded $10 \%$. Fig.13 shows the relationships between the earthquake intensities at period $T_{l}$ 353 and maximum story lateral drift $R_{p}$. Based on the IDA results, the seismic fragilities of the archetypes 354 were estimated by a lognormal cumulative distribution function (Vossoghi and Saiidi 2012; Muntasir and 355 Alam 2014; Baker 2015), shown in Eqs. (6) and (7). Furthermore, the logarithmic standard deviation of 356 Sa (T1) was calculated by Eq. (6).

$$
\begin{aligned}
& P=\left[C / S a\left(T_{1}\right)=x\right]=\Phi\left(\frac{\ln (x / \mu)}{\beta}\right) \\
& \beta=\sqrt{\frac{1}{n-1} \sum_{i=1}^{n}\left(\ln \left(\frac{S_{a}\left(T_{1}\right)}{\mu}\right)\right)^{2}}
\end{aligned}
$$
$=$ the selected amount of GMs.

The FEMA 356 guideline (FEMA 2000) defines four limit-states to elaborate the seismic damage status of building structures: immediate occupancy (IO), life safety (LS), collapse prevention (CP), and collapse. IO, LS, and CP are assigned when the maximum lateral inter-story drifts of $1.0 \%, 2.0 \%$, and 4.0\%, respectively. FEMA P-58-1 (FEMA 2009) defines collapse as one of the following scenarios: sidesway failure (lateral dynamic instability) characterized by loss of lateral stiffness and development of Pdelta instability, loss of vertical-load carrying capacity of gravity or seismic-force-resisting components 
owing to earthquake-induced drifts, and exceedance of non-simulated failure criteria consisting of force or deformation limits beyond which components cannot reliably resist the load. For simplicity, the maximum lateral inter-story drift of $10.0 \%$ was assumed as the collapse limit state (Tarfan et al. 2019). This rule was also adopted in this study.

Fig.14 shows the seismic fragility probabilities of the exceedances of the IO, LS, CP, and collapse limit states of both five-floor and ten-floor archetypes. As indicated, for the IO and LS limit states, the possibility curves of the five-floor archetypes with LBHSRs were larger than those of the five-floor archetypes with HBNSRs. Moreover, the median collapse capacity $S_{C T}$ representing half of the GMs caused the limit state of the five-floor archetypes with HBNSRs to be the largest. Comparing the CP and collapse limit states, it was observed that the possibility of the archetype with HBNSRs was the highest. This implies that the use of LBHSR could reduce the likelihood of CP and seismic collapse limit states. Furthermore, larger the LR, lower is the likelihood. The above statements indicate that the use of LBHSR had no apparent effect on the resistance to the marginal seismic limit states such as IO and LS. However, it was favourable to the CP and seismic collapse limit states. Furthermore, higher the LR of LBHSR, lower is the likelihood of seismic collapse. A similar conclusion can be obtained by observing the possibility curves of the ten-floor archetypes. Comparing the probability curves of the IO, LS, and CP limit states, the possibility curves of the ten-floor archetype with LBHSRs (LR $=3.14 \%$ and $2.09 \%$ ) were larger than that of the ten-floor archetype with HBNSRs having an LR of 3.14\%. However, the possibility curves of the seismic collapse limit state of the ten-floor archetypes with LBHSRs (LR $=3.14 \%$ and 2.09\%) were significantly smaller compared with the HBNSR scenario. Moreover, the advantage of using LBHSR was more apparent for the IO, LS, and CP limit states of the five-floor archetype than for those of the ten-floor archetype. However, a comparison of the difference in the possibility curves of the archetypes with HBNSRs and LBHSRs revealed that the application of LBHSR in the ten-floor archetype was more effective for resisting the collapse limit state. The collapse margin ratio $(C M R)$ is used to 
394 represent seismic safety and is defined as the ratio of the $S_{C T}$ to the 5\%-damped spectral acceleration of 395 the MCE GMs at the fundamental period, $S_{a}\left(T_{1}\right)$ (FEMA 2009). The $C M R$ s of all the building archetypes 396 with different longitudinal reinforcement scenarios at four SDCs of Chinese seismic code (GB 50011397 2010) are shown in Table 1. As is evident, although the seismic resistance of the archetype with LBHSRs 398 having a lower LR of $2.09 \%$ was similar to that of the archetype with HBNSRs having an LR of 3.14\%, 399 the CMRs of the former at each SDC were increased by $6.7 \%$ and $13.75 \%$ compared with the latter for 400 the five-floor archetype and ten-floor archetype, respectively. Furthermore, when the LR of LBHSR was 401 increased from $2.09 \%$ to $3.14 \%$, the increase ratio was enhanced further to $26.51 \%$ and $33.75 \%$ for the 402 five-floor archetype and ten-floor archetype, respectively. Hence, it was concluded that the global seismic 403 response of an RC building frame is substantially affected by the use of LBHSR. The effect of LBHSR is 404 more apparent when the building frame experiences a large deformation level such as the collapse limit 405 state.

\section{Post-earthquake reparability and evaluation of residual story lateral drift of archetype}

\subsection{Analysis of fragility of residual story lateral drift}

Residual deformation has been used as an index to estimate the post-earthquake damage of buildings,

411 from the onset of damage of nonstructural components to near-collapse of the structure. The residual 412 story drift ratios $\Delta / h$ of DS1, DS2, and DS3 are defined as $0.2 \%, 0.5 \%$, and $1.0 \%$, respectively. 413 Meanwhile, the $\Delta / h$ of the DS4 damage state for limited, moderate, and high ductility systems are $1.0 \%$, $4142.0 \%$, and $4.0 \%$, respectively. DS1 represents the state wherein no structural realignment is necessary for 415 structural stability, and the adjustment and repair of only certain nonstructural and mechanical 416 components that are sensitive to elevator rails, curtain walls, and doors are required. DS2 represents a 417 realignment of the structural frame and related structures are need to be maintained, limited degradation 
418 in structural stability is permitted to occur in nonstructural and mechanical components. DS3 represents

419 the scenario where significant structural realignment is required to restore the margin-of-safety for lateral 420 stability. Furthermore, the repair of the structure is not economically or practically feasible. DS4 421 represents the scenario wherein the structure is in danger of collapse after an earthquake owing to an 422 excessive residual drift.

423 The relationships between earthquake intensity and the residual story lateral drift of archetypes with 424 HBNSRs and LBHSRs are shown in Fig.15. As is evident from the figure, the increase in the stiffness of 425 the fragility curves of the archetypes with LBHSRs was larger than that for the archetypes with HBHSRs. 426 This was particularly so for identical LR. Moreover, the number of residual story lateral drifts higher than $4272.0 \%$ of the archetype with LBHSRs having an LR of $3.14 \%$ is not adequate for a residual drift fragility 428 analysis similar to the one for the other two longitudinal reinforcement scenarios. As shown in Fig.10, the 429 pushover curves of both archetypes indicate that the building frame could be assumed to be a moderate 430 ductility system. Consequently, only the DS1, DS2, and DS3 damage states of the archetypes were 431 compared in this study.

432 The comparisons of the possibility curves of three damage states of the archetypes with HBNSRs and 433 LBHSRs are shown in Fig.16. As is evident from the figure, regardless of the damage states, both five434 floor and ten-floor archetypes with LBHSRs generally exhibited significantly smaller probability 435 compared with that for the archetypes with HBNSRs. Although the archetypes with HBNSRs having an 436 LR of $3.14 \%$ and LBHSRs having an LR of $2.09 \%$ had similar seismic resistance (see Fig.10), the 437 possibility curve of the archetype with LBHSRs having an LR of $2.09 \%$ was smaller than that of the 438 archetype with HBNSRs having an LR of 3.14\%. Moreover, when the LR of LBHSR was increased from $4392.09 \%$ to $3.14 \%$, the possibility curve of the archetype was decreased further, as shown in Fig.16. This 440 implies that the low-bond property of longitudinal reinforcement influences the reduction in the residual 441 deformation of building frames. A closer inspection reveals that the LBHSR is more effective for 
442 mitigating the residual drift for the low-rise five-floor building archetype. Furthermore, the possibility

443 curves of archetypes are similar at marginal earthquake intensity regardless of the type and LR of 444 longitudinal reinforcement. In addition, the difference in the possibility curves is increased with the 445 increase in the earthquake intensity. It can be concluded that the use of LBHSR is highly effective for 446 reducing the residual deformation of an $\mathrm{RC}$ building frame. Furthermore, it is more effective when the 447 building is subjected to a large earthquake. 457 estimated using the proposed equations in the JRA and FEMA codes.

458 The equations to calculate the residual drift of structure proposed by FEMA P58-1 (FEMA 2012) is as 459 follows:

\subsection{Evaluation of residual story lateral drift}

The previous study determined that the residual deformation of structures is significantly related to the ratio of post-yield stiffness to yield stiffness. However, it is not dependent on the natural fundamental period, soil condition, or ductility (Tarfan et al. 2019). Japan Road Association (JRA) (JRA 2017) and Federal Emergency Management Agency (FEMA) of United States (FEMA 2012) proposed certain equations for evaluating the residual deformation of bridge and building structures based on the study results of Kawashima et al. (Tarfan et al. 2019; JRA 2017) and Christopoulos et al. (Christopoulos et al. 2003; Pampanin et al. 2008). Therefore, the residual story lateral drift of the building archetype can be

The equations to calculate the residual drift of structure proposed by FEMA P58-1 (FEMA 2012) is as

$$
R_{r d}= \begin{cases}0 & R_{p} \leq R_{y} \\ 0.3\left(R_{p}-R_{y}\right) & R_{y} \leq R_{p} \leq 4 R_{y} \\ \left(R_{p}-3 R_{y}\right) & R_{p} \geq 4 R_{y}\end{cases}
$$

463 Kawashima (1997) extensively studied the residual drift of engineering structures subjected to an 
earthquake. They proposed the following equation, which has been adopted by the JRA code (JRA 2017):

$$
R_{r d}=C_{R}\left(\mu_{r}-1\right)(1-r) R_{y}
$$

where $R_{r d}=$ residual lateral drift, $C_{R}=$ correction coefficient $(=0.6), \mu_{r}=$ response ductility, $r=$ ratio of the post-yielding stiffness to initial yield stiffness, and $R_{y}=$ yield story lateral drift.

As shown in Eqs. (8) and (9), the residual lateral drift is determined by the yield story lateral drift $R_{y}$ and coefficient $r$. To obtain these two factors, the relationships between the lateral story shear force and the lateral drift of the collapse story of the archetypes were determined according to the static pushover results. Subsequently, $R_{y}$ and $r$ were calculated. Furthermore, the average of the results of the three methods (namely, first yield, the geometric graphic method, and the equivalent elastoplastic energy method proposed by Park) was adopted as $R_{y}$ (Park 1989).

Fig. 17 shows comparisons between the predicted (using the FEMA and JRA codes) and IDA results of the residual story lateral drifts of both the archetypes. As indicated, the residual story lateral drifts of both the archetypes with different types and LRs of longitudinal reinforcements were generally overestimated. The average values of the ratios of predicted results to IDA results (Pred./IDA) are 2.61 and 4.11 for the FEMA and JRA codes, respectively. The standard deviations of the FEMA and JRA codes are 6.13 and 9.52, respectively, whereas the maximum Pred./IDA of the FEMA and JRA codes are 62.02 and 98.19, respectively. The results indicate that the prediction using the FEMA code was generally better than that using the JRA code. The comparison results imply that the calculation models proposed by the current provisions are not capable of predicting the residual story lateral drifts of RC building frames with good accuracy. It is necessary to conduct investigations to further refine the equation for predicting residual deformation. 


\section{Conclusions}

488 The authors proposed the use of low-bond high-strength reinforcement (LBHSR) as longitudinal rebar 489 to develop a self-centring RC column. This study further investigated the seismic fragility and post490 earthquake reparability of RC building frames with the proposed columns based on the IDA results. A 491 smaller longitudinal reinforcement ratio of LBHSR was assumed for designing the similar seismic 492 resistance of the archetype to investigate the influence of the low-bond property on the seismic response. 493 In addition, the longitudinal reinforcement ratio of LBHSR and HBNSR was assumed to be identical to 494 study the effect of longitudinal reinforcement ratio. The results of this study could be summarized as 495 follows:

496 1. Notwithstanding similar seismic base shear force resistance, the use of LBHSR with a lower LR can improve the yield roof lateral drift and ultimate lateral drift (at $0.8 \mathrm{~V}$ ) of both low-rise and mid-rise building frame archetypes owing to the low-bond property. Furthermore, higher the longitudinal reinforcement ratio (LR), better are the results.

2. The stiffness of the archetype with LBHSRs was decreased from a certain lateral drift because of the bond-slip of the LBHSR. Furthermore, an increase in the LR could increase the stiffness.

3. The dynamic response results indicated that the LBHSR was highly effective for reducing the seismic lateral drift responses only for the structure subjected to a high-intensity earthquake. However, its use effectively reduced the residual story lateral drift regardless of the earthquake intensity.

4. The seismic fragility curves indicate that LBHSR is more effective for preventing seismic collapse as well as for attaining a higher LR and lower collapse probability. However, the advantage is limited for the IO, LS, and CP limit states.

5. The fragility curves of the residual story lateral drifts of both the archetypes show that the LBHSR can substantially reduce the exceedance probability of the damage states DS1, DS2, and DS3. 
Furthermore, the effectiveness is increased with the increase in the LR and earthquake intensity.

\section{Compliance with ethical standards}

Conflict of interest: The authors declare that there is no conflict of interest regarding the publication of this paper.

Ethical approval: Authors state that the research was conducted according to ethical standards.

\section{References}

Architectural Institute of Japan (AIJ). (2016) AIJ standard for lateral load-carrying capacity calculation of reinforced concrete structures. Architectural Institute of Japan, Tokyo, Japan.

ASCE/SEI 7-10. (2010) Minimum design loads for buildings and other structures. American Society of Civil Engineers/Structural Engineering Institute.

Alath S, Kunnath SK (1995) Modeling inelastic shear deformation in RC beam-column joints. Engineering Mechanics: Proceedings of $10^{\text {th }}$ Conference: University of Colorado at Boulder, 
Boulder, Colorado, May 21-24, 1995, American Society of Civil Engineers, New York, 2:822-825.

536 Baker JW. (2015) Efficient analytical fragility function fitting using dynamic structural analysis. $537 \quad$ Earthquake Spectra 31(1): 579-599.

538 Christopoulos C, Pampanin S, Priestley MJN (2003) Performance-based seismic response of frame structrues including residual deformations. Part I: single-degree of freedom systems. Journal of Earthquake Engineering 7(1): 97-118. DOI: 10.1080/13632460309350443

Federal Emergency Management Agency (FEMA). (2012) Seismic Performance Assessment of Buildings - Vol. 1 Methodology, FEMA P-58-1.

Funato, Y., Sun, Y.P., Takeuchi, T., Cai, G.C (2012) Modeling and application of bond characteristic of high-strength reinforcing bar with spiral grooves. Proceedings of the Japan Concrete Institute 34(2): 157-162. (in Japanese)

Federal Emergency Management Agency (FEMA). (2009) Quantification of building seismic performance factors FEMA P695.

Federal Emergency Management Agency (FEMA). (2000) Prestandard and commentary for the seismic rehabilitation of building. FEMA 356, Rehabilitation.

GB/T 5223.3-2017. (2017) Steel bars for the prestressing of concrete [ISO 6934-3:1991, steel for presstessing of concrete-Part 3: Quenched and tempered wire, NEQ]. General Administration of Quality Supervision, Inspection and Quarantine of the People's Republic of China, Standardization Administration of China.

GB 50011-2010. (2010) Code for seismic design of building. Ministry of Housing and Urban-Rural Development of the People's Republic of China (MOHURD), Beijing, China.

Housner GW (1963) The behavior of inverted pendulum structures during earthquakes. Bulletin of the Seismological Society of America 53 (2): 403-417.

Japan Road Association (JRA). (2017) Specifications for highway bridges, Part 4, Seismic design. Tokyo, Japan. 
Japan Road Association (JRA). (2017) Specifications for highway bridges, Part 4, Seismic design. Tokyo, $561 \quad$ Japan.

562 Kurama C, Sause R, Pessiki S, et al. (1999) Lateral load behavior and seismic design of unbonded post-

Kurama YC, Shen Q (2008) Seismic design and response evaluation of unbonded post-tensioned hybrid coupled wall structures. Earthquake Engineering and Structural Dynamics 37(14): 1677-1702.

Kawashima K (1997) The 1996 Japanese Seismic Design Specifications of Highway Bridges and the Performance-Based Design. Proceedings of International Conference at Bled, Slovenia, pp: 229240.

Kim J, and LaFave JM (2008) Probabilistic joint shear strength models for design of RC beam-column connections. ACI Structural Journal 105: 770-780.

Kim J, LaFave JM, Song J (2009) Joint shear behavior of RC beam-column connections. Magazine of Concrete Research 61: 119-132.

Kim J, and LaFave JM (2007) Key influence parameters for the joint shear behaviour of reinforced concrete (RC) beam-column connections. Engineering Structures 29: 2523-2539.

Lam L and Teng JG (2003) Design-oriented stress-strain model for FRP-confined concrete in rectangular columns. Journal of Plastic and Composite 22(13): 1149-1186.

Lodhi MS, Sezen H (2012) Estimation of monotonic behavior of reinforced concrete columns considering shear-flexure-axial load interaction. Earthquake Engineering and Structural Dynamics 41:21592175. DOI: $10.1002 /$ eqe. 2180 .

MacRae GA, Kawashima K (1997) Post-earthquake residual displacements of bilinear oscillator. Earthquake Engineering and Structural Dynamics 26(7): 701-716.

MacRae G (2013) Low Damage construction some systems issues. Proceedings of the 10th International Conference on Urban Earthquake Engineering, Tokyo, Japan.

Muntasir Billah AHM, Alam AS (2014) Seismic performance evaluation of multi-column bridge bents 
retrofitted with different alternatives using incremental dynamic analysis. Engineering Structures 62-63: $105-117$.

Opensees. (2018) Open system for earthquake engineering simulations. Version 2.5.0, Berkeley, CA. http://opensees.berkeley.edu

Restrepo I, Rahman A. (2007) Seismic performance of self-centering structural walls incorporating energy dissipaters. Journal of Structural Engineering, 133(11): 1560-1570.

Roke DA, Chandra A, Q. Huang Q, Sett K (2013) Methodology for life cycle cost assessment of selfcentering concentrically braced frame systems. Proceedings of the 10th International Conference on Urban Earthquake Engineering, Tokyo, Japan.

Stevenson M, Panian L, Korolyk M, et al. (2008) Post-tensioned concrete walls and frames for seismic resistance - a case study of the David Brower Center. Proceedings of the SEAOC Annual Convention, Hawaii, US.

Sun YP, Sakino K, Yoshimoto A (1996) Flexural behavior of RC columns confined by rectilinear reinforcement. Journal of Structural and Construction Engineering 486: 94-105.

Sezen H, Setzler EJ (2008) Reinforcement slip in reinforced concrete columns. ACI Structural Journal 105(3): 280-289.

Sezen H, Chowdhury T (2009) Hysteretic model for reinforced Concrete columns including the effect of shear and axial load failure. Journal of Structural Engineering (ASCE) 135(2): 139-146. 
610 Tarfan S, Banazadeh M, Esteghanati MZ (2019) Probability seismic assessment of non-ductile RC buildings retrofitted using pre-tensioned aramid fiber reinforced polymer belts. Composite Structures 208: 865-878.

613 Vosooghi A, Saiidi MS (2012) Experimental fragility curves for seismic response of reinforced concrete

Wang JH, Zhao H (2018) High performance damage-resistant seismic resistant structural systems for sustainable and resilient city: A Review. Shock and Vibration 2018(8703697). https://doi.org/$\underline{10.1155 / 2018 / 8703697 .}$.

Wang JH, Kunnath S, He J, Xiao Y (2020) Fire resistance and post-fire residual seismic performances of circular concrete-filled steel tubular columns. ASCE Journal of Structural Engineering 146(6): 04020105. DOI: 10.1061/(ASCE)ST.1943-541X.0002632

Wang JH, Sun YP (2020a) Influence of bond property of longitudinal bars on seismic behaviors of RC columns. Magazine of Concrete Research 72(15): 778-798. https://doi.org/10.1680/jmacr.-18.00563.

Wang JH, Sun YP (2020b) Equivalent stress block to characterise force-displacement behaviour of circular RC column considering steel bond slip. Magazine of Concrete Research 72(22): 1171-1188. https://doi.org/10.1680/jmacr.19.00104.

Wang JH, Zhao H, He J (2019) Seismic behaviors and resilient capacity of CFRP-confined concrete columns with partially debonded high-strength steel rebars. Composite Structures 222: 110912.

Wang JH, Sun YP, Takashi T, Koyama T (2020) Seismic behavior of circular fly ash concrete columns reinforced with low-bond high-strength steel rebar. Structures 27: 1335-1357. https://doi.org/10.1016/j.istruc.2020.07.005

Wang JH. (2021) Cyclic behaviors of reinforced concrete beam-column joints debonded reinforcements and beam failure: experiment and analysis. Bulletin of Earthquake Engineering 19: 101-133. DOI: 10.1007/s10518-020-00974-1. 
634 Wang JH, Cai GC, Larbi AS (2021) Lateral behavior of rectangular concrete columns reinforced by 635 partially debonded high-strength reinforcements based on a proposed equivalent stress block. 636 Bulletin of Earthquake Engineering 19(4): 1901-1930. http://doi.org/10.1007/s10518-021-01043-x 637 Zibaei H, Mokari J (2014) Evaluation of seismic behavior improvement in RC MRFs retrofitted by 638 controlled rocking wall systems. The Structural Design of Tall and Special Buildings, 23(13): 995$639 \quad 1006$.

640 
Table 1. Basic information of building archetypes

\begin{tabular}{|c|c|c|c|c|c|c|c|}
\hline \multicolumn{2}{|c|}{ Archetype } & \multicolumn{3}{|c|}{ Five-floor } & \multicolumn{3}{|c|}{ Ten-floor } \\
\hline \multirow{3}{*}{$\begin{array}{l}\text { Column } \\
\text { longitudinal } \\
\text { rebar }\end{array}$} & Type & HBNSR & \multicolumn{2}{|c|}{ LBHSR } & HBNSR & \multicolumn{2}{|c|}{ LBHSR } \\
\hline & Number & $16-\mathrm{D} 25$ & $\begin{array}{c}\text { 12-D22+ } \\
4-D 12\end{array}$ & 16-D25 & $16-\mathrm{D} 25$ & $\begin{array}{c}\text { 12-D22+ } \\
4-D 12\end{array}$ & $16-\mathrm{D} 25$ \\
\hline & $\operatorname{LR}(\%)$ & 3.14 & 2.09 & 3.14 & 3.14 & 2.09 & 3.14 \\
\hline \multicolumn{2}{|l|}{ Height (m) } & \multicolumn{3}{|c|}{16.0} & \multicolumn{3}{|c|}{32.0} \\
\hline \multicolumn{2}{|l|}{$\mathrm{T}_{1}(s)$} & \multicolumn{3}{|c|}{0.5} & \multicolumn{3}{|c|}{1.0} \\
\hline \multicolumn{2}{|l|}{$\mathrm{S}_{\mathrm{a}, \mathrm{MCE}}(g)$} & \multicolumn{3}{|c|}{0.4} & \multicolumn{3}{|c|}{0.2336} \\
\hline \multicolumn{2}{|l|}{$V_{m}(k N)$} & \multicolumn{3}{|c|}{1168.0} & \multicolumn{3}{|c|}{1140.4} \\
\hline \multicolumn{2}{|l|}{$\Omega$} & 1.24 & 1.26 & 1.62 & 1.23 & 1.27 & 1.43 \\
\hline \multicolumn{2}{|l|}{$R_{y, e f f}(\%)$} & 0.74 & 1.10 & 2.08 & 0.41 & 0.71 & 0.77 \\
\hline \multicolumn{2}{|l|}{$\mu_{T}$} & 10.76 & 6.61 & 9.03 & 6.42 & 6.72 & 7.65 \\
\hline \multirow{4}{*}{$C M R$} & SDC Six & 74.50 & 79.50 & 94.25 & 40.00 & 45.50 & 53.50 \\
\hline & SDC Seven & 24.83 & 26.50 & 31.41 & 13.33 & 15.17 & 17.83 \\
\hline & SDC Eight & 12.42 & 13.25 & 15.71 & 6.67 & 7.58 & 8.92 \\
\hline & SDC Nine & 9.31 & 9.94 & 11.78 & 5.00 & 5.69 & 6.69 \\
\hline
\end{tabular}

3 Note: $D=$ diameter of longitudinal reinforcement; $L R=$ longitudinal rebar ratio; $T_{1}=$ fundamental period;

$4 S_{a, M C E}=$ maximum considered earthquake spectral acceleration; $V_{m}=$ base shear force calculated 5 according to the designed earthquake spectral acceleration; $\Omega=$ Over-strength factor; $R_{y, \text { eff }}=$ effective 6 yield roof lateral drift ratio; $\mu_{T}=$ period-based ductility; $C M R=$ collapse margin ratio. 
Table 2. Information of earthquake motions for nonlinear time-history analysis

\begin{tabular}{|c|c|c|c|c|c|c|c|c|c|}
\hline \multirow[b]{2}{*}{ No. } & \multicolumn{5}{|c|}{ Earthquake } & \multirow{2}{*}{$\begin{array}{c}\text { Recording Station } \\
\text { Name }\end{array}$} & \multirow{2}{*}{$\begin{array}{l}\text { PGA } \\
(\mathrm{g})\end{array}$} & \multirow{2}{*}{$\begin{array}{l}\text { DT } \\
\text { (s) }\end{array}$} & \multirow{2}{*}{$\begin{array}{l}\text { Duration } \\
\text { Time (s) }\end{array}$} \\
\hline & RSN. & Mag. & Year & Name & $R_{\text {rup }}(\mathrm{km})$ & & & & \\
\hline \multicolumn{10}{|c|}{ Far-field (FF) } \\
\hline 1 & 953 & 6.7 & 1994 & Northridge & 17.15 & Beverly Hills-Mulhol & 0.15 & 0.01 & 20.00 \\
\hline 2 & 960 & 6.7 & 1994 & Northridge & 12.40 & Canyon Country-WLC & 0.48 & 0.01 & 20.00 \\
\hline 3 & 1602 & 7.1 & 1999 & Duzce, Turkey & 12.04 & Bolu & 0.74 & 0.01 & 55.90 \\
\hline 4 & 1787 & 7.1 & 1999 & Hector Mine & 11.70 & Hector & 0.34 & 0.01 & 45.31 \\
\hline 5 & 1111 & 6.9 & 1995 & Kobe, Japan & 7.10 & Nishi-Akashi & 0.51 & 0.01 & 40.96 \\
\hline 6 & 1116 & 6.9 & 1995 & Kobe, Japan & 19.15 & Shin-Osaka & 0.23 & 0.01 & 40.96 \\
\hline 7 & 900 & 7.3 & 1992 & Landers & 23.60 & Yermo Fire Station & 0.24 & 0.02 & 44.00 \\
\hline 8 & 848 & 7.3 & 1992 & Landers & 19.74 & Coolwater & 0.28 & 0.02 & 44.00 \\
\hline 9 & 1633 & 7.4 & 1990 & Manjil, Iran & 12.55 & Abbar & 0.52 & 0.02 & 53.52 \\
\hline 10 & 725 & 6.5 & 1987 & Superstition Hills & 11.20 & Poe Road (temp) & 0.45 & 0.01 & 22.30 \\
\hline \multicolumn{10}{|c|}{ Near-field: Pulse Records Subset (NFP) } \\
\hline 11 & 723 & 6.5 & 1987 & Superstition Hills-02 & 3.50 & Parachute Test Site & 0.42 & 0.01 & 22.35 \\
\hline 12 & 828 & 7.0 & 1992 & Cape Mendocino & 8.18 & Petrolia & 0.59 & 0.02 & 36.00 \\
\hline 13 & 1063 & 6.7 & 1994 & Northridge-01 & 6.50 & Rinaldi Receiving Sta & 0.87 & 0.01 & 20.00 \\
\hline 14 & 1086 & 6.7 & 1994 & Northridge-01 & 5.30 & Sylmar - Olive View & 0.73 & 0.02 & 40.00 \\
\hline 15 & 1605 & 7.1 & 1999 & Duzce, Turkey & 6.58 & Duzce & 0.40 & 0.005 & 26.00 \\
\hline \multicolumn{10}{|c|}{ Near-field: No Pulse Records Subset (NFNP) } \\
\hline 16 & 126 & 6.8 & 1976 & Gazli, USSR & 5.50 & Karakyr & 0.71 & 0.0066 & 13.52 \\
\hline 17 & 160 & 6.5 & 1979 & Imperial Valley-06 & 2.66 & Bonds Corner & 0.60 & 0.01 & 51.60 \\
\hline 18 & 165 & 6.5 & 1979 & Imperial Valley-06 & 8.40 & Chihuahua & 0.28 & 0.01 & 51.60 \\
\hline 19 & 825 & 7.0 & 1992 & Cape Mendocino & 6.96 & Cape Mendocino & 1.49 & 0.02 & 30.00 \\
\hline 20 & 1048 & 6.7 & 1994 & Northridge-01 & 12.10 & Northridge - Saticoy & 0.42 & 0.01 & 30.00 \\
\hline
\end{tabular}




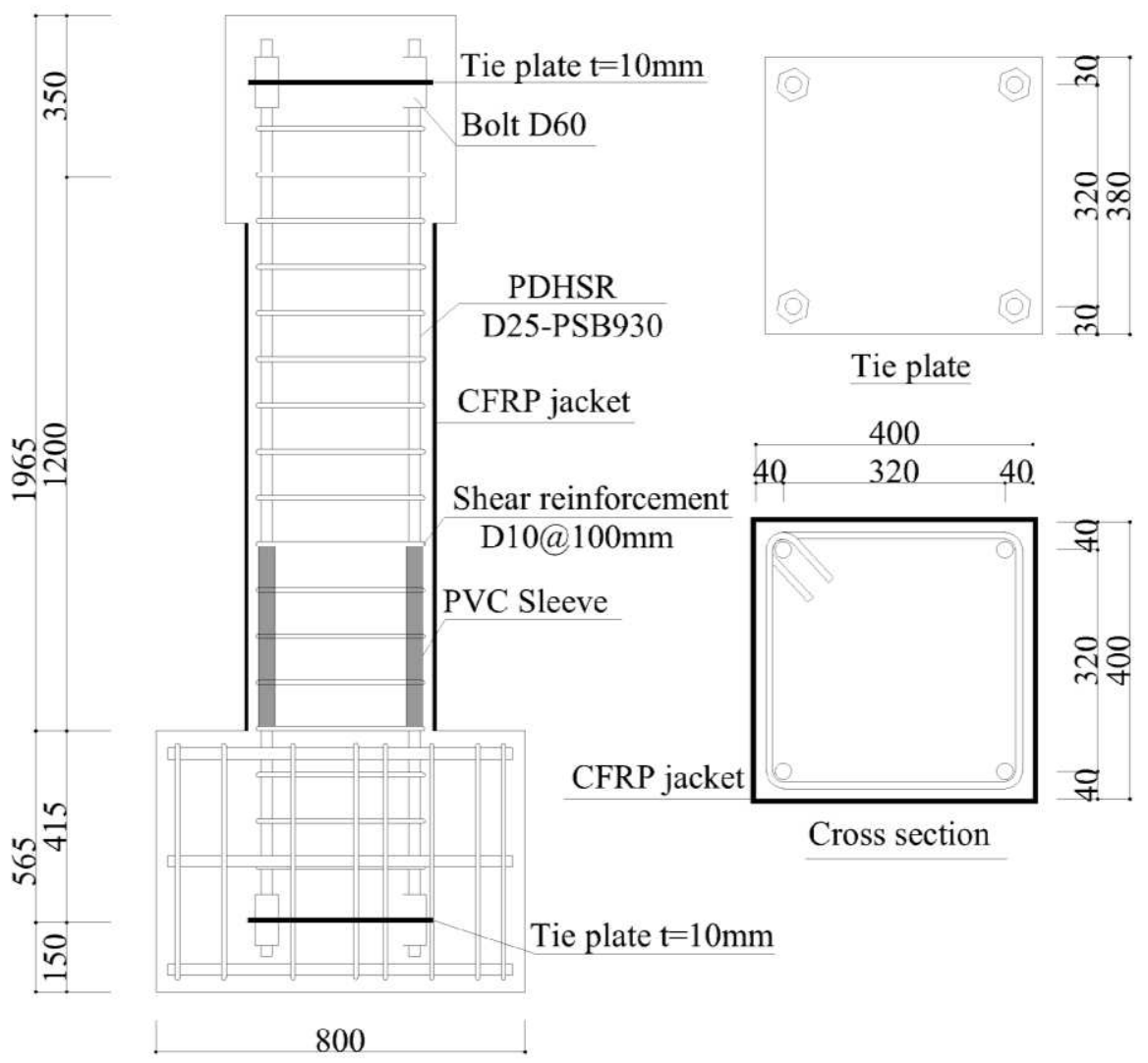

(a)

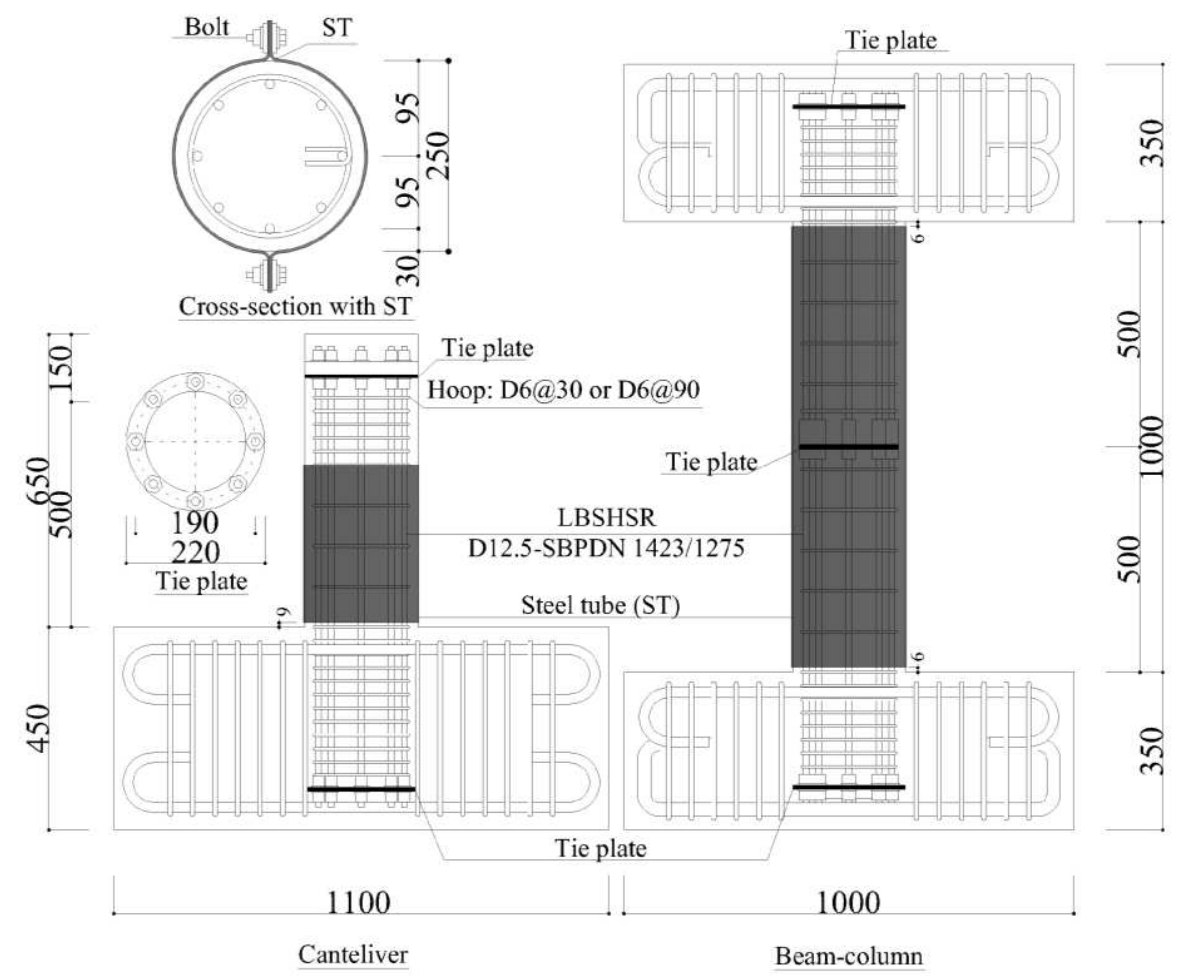

(b)

Fig. 1. Reinforcement details of the proposed RC columns (units: mm): (a) with PDHSRs; (b) with LBSHSRs 


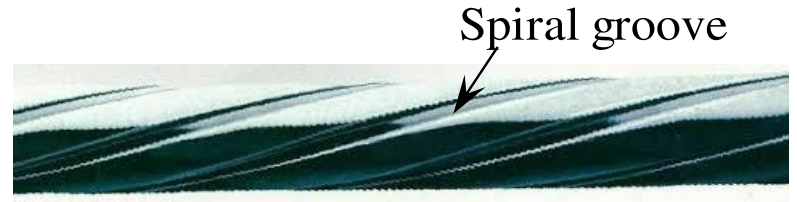

(a) SBPDN 1275/1420 rebar

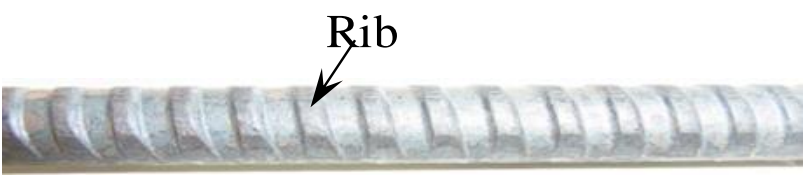

(b) USD 685 rebar

Fig.2. High-strength reinforcement with different bond strength levels

4 

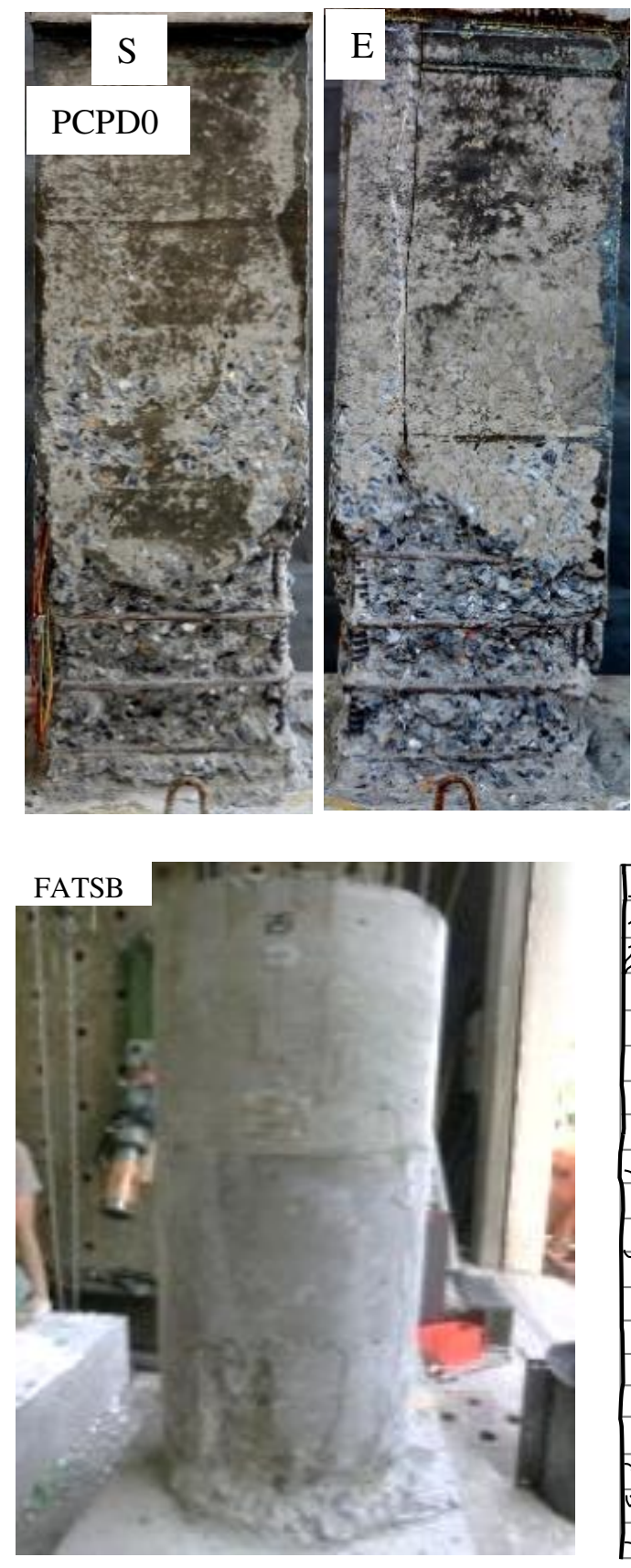

Cantilever

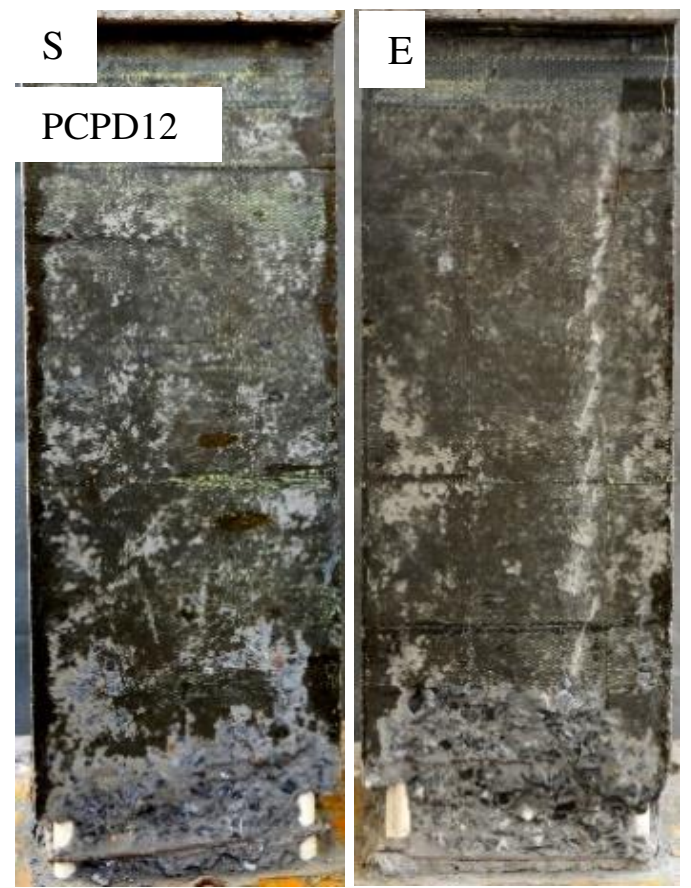

(a)

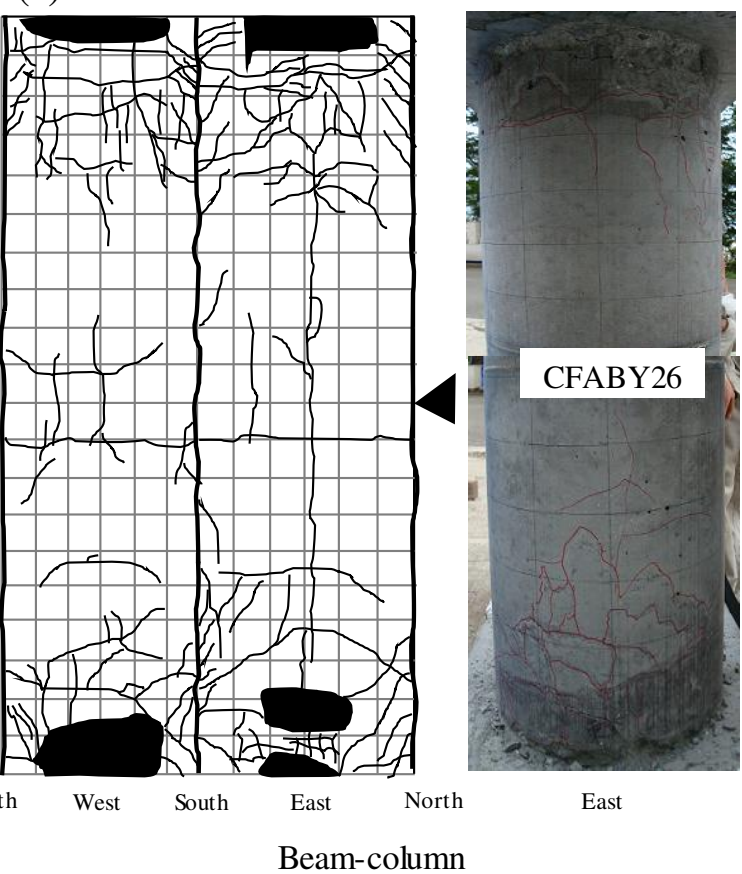

(b)

Fig. 3. Typical seismic damages of test columns with LBHSRs: (a) RC columns with PDHSRs; (b) RC columns with LBSHSRs 


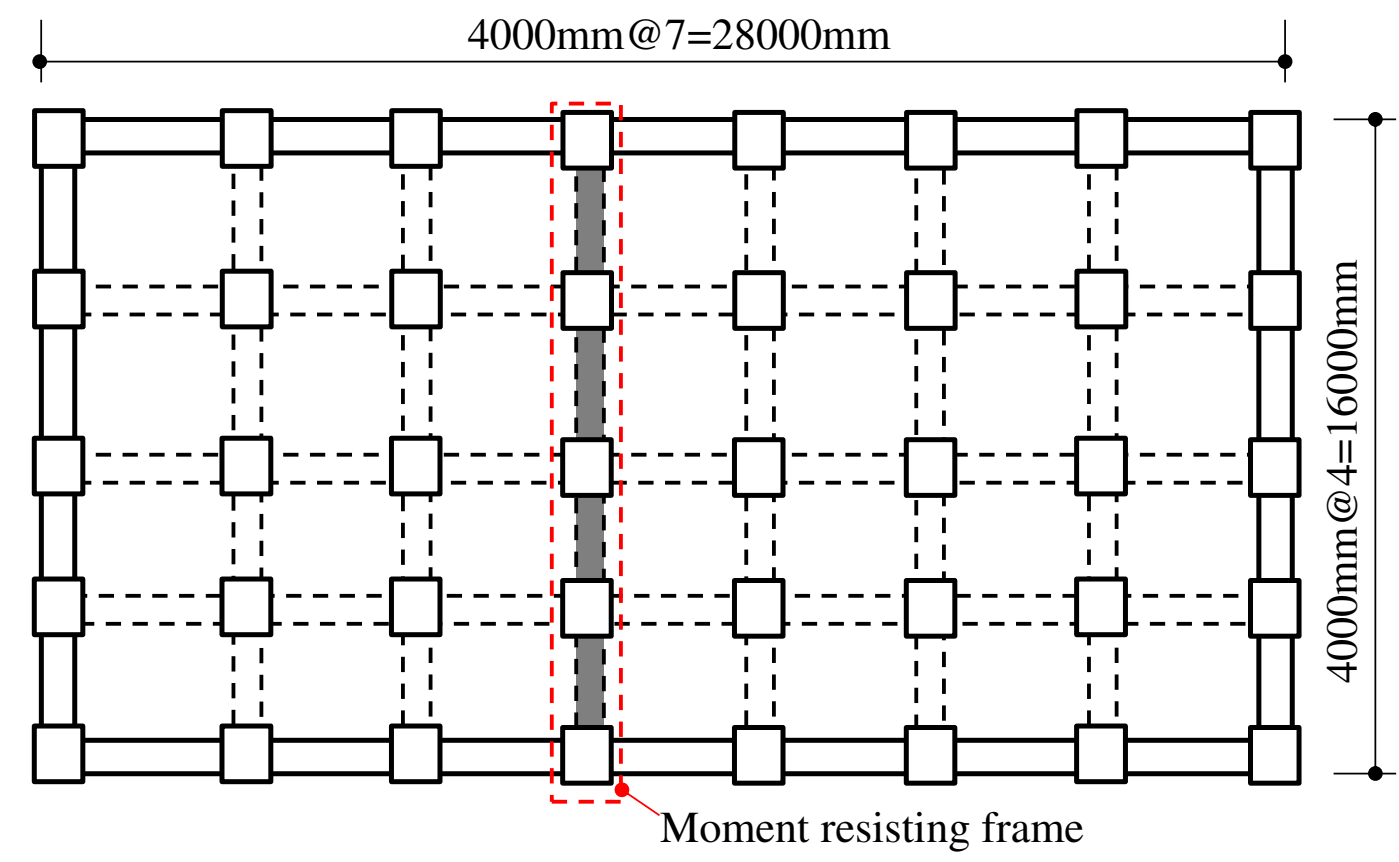

(a)
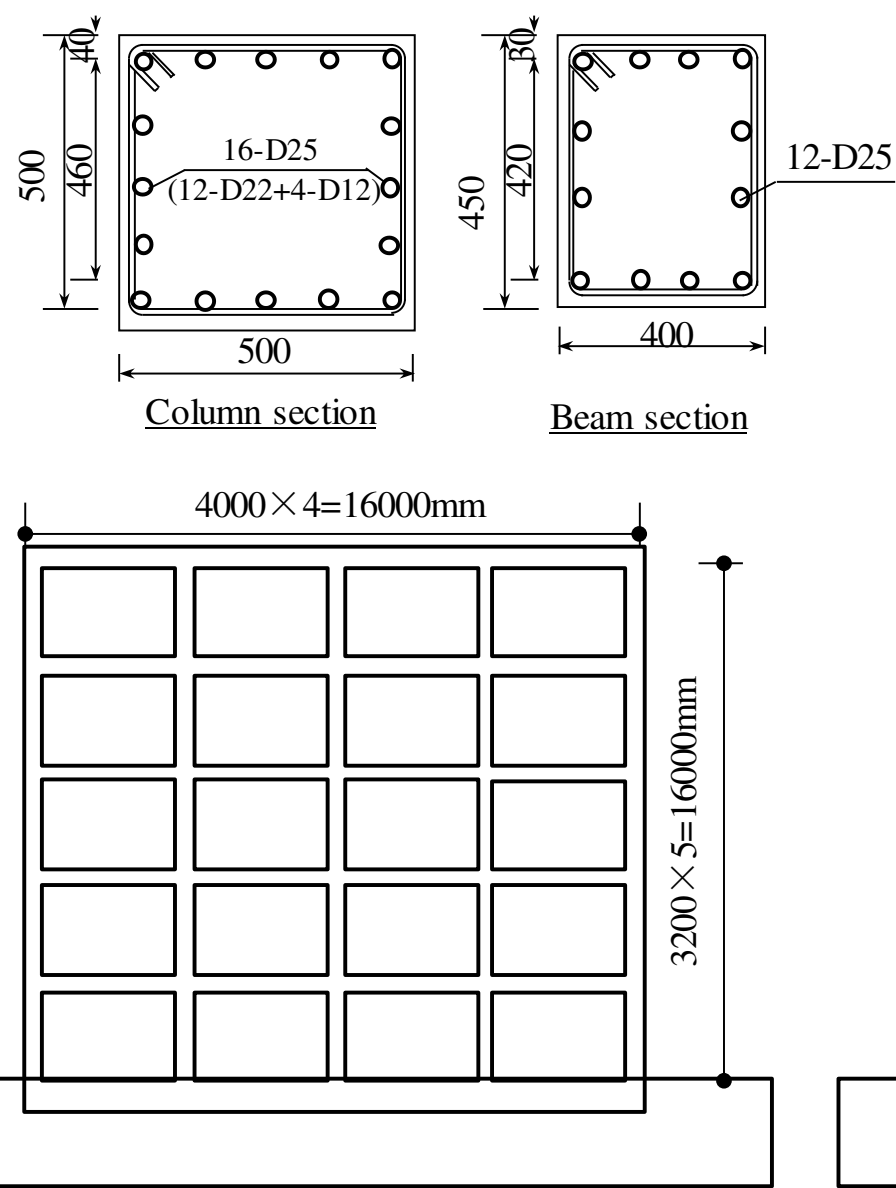

(b)

Fig.4. Building frame archetypes: (a) plain view; (b) elevation 


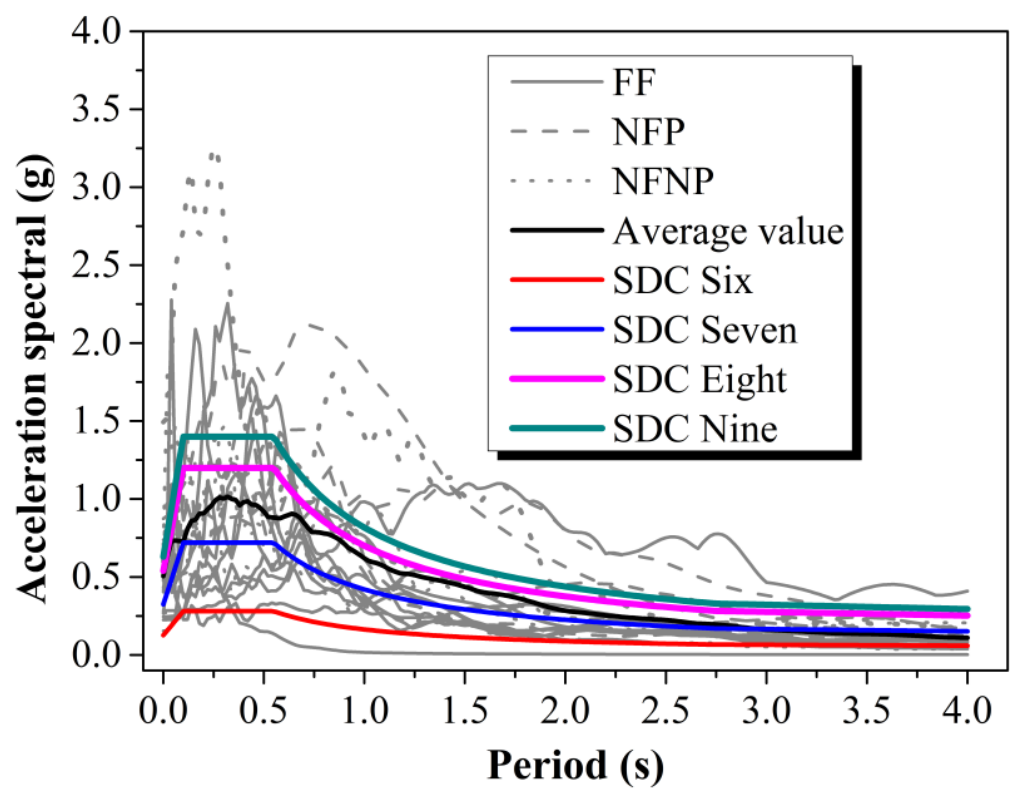

Fig.5. Acceleration spectral of ground motions 


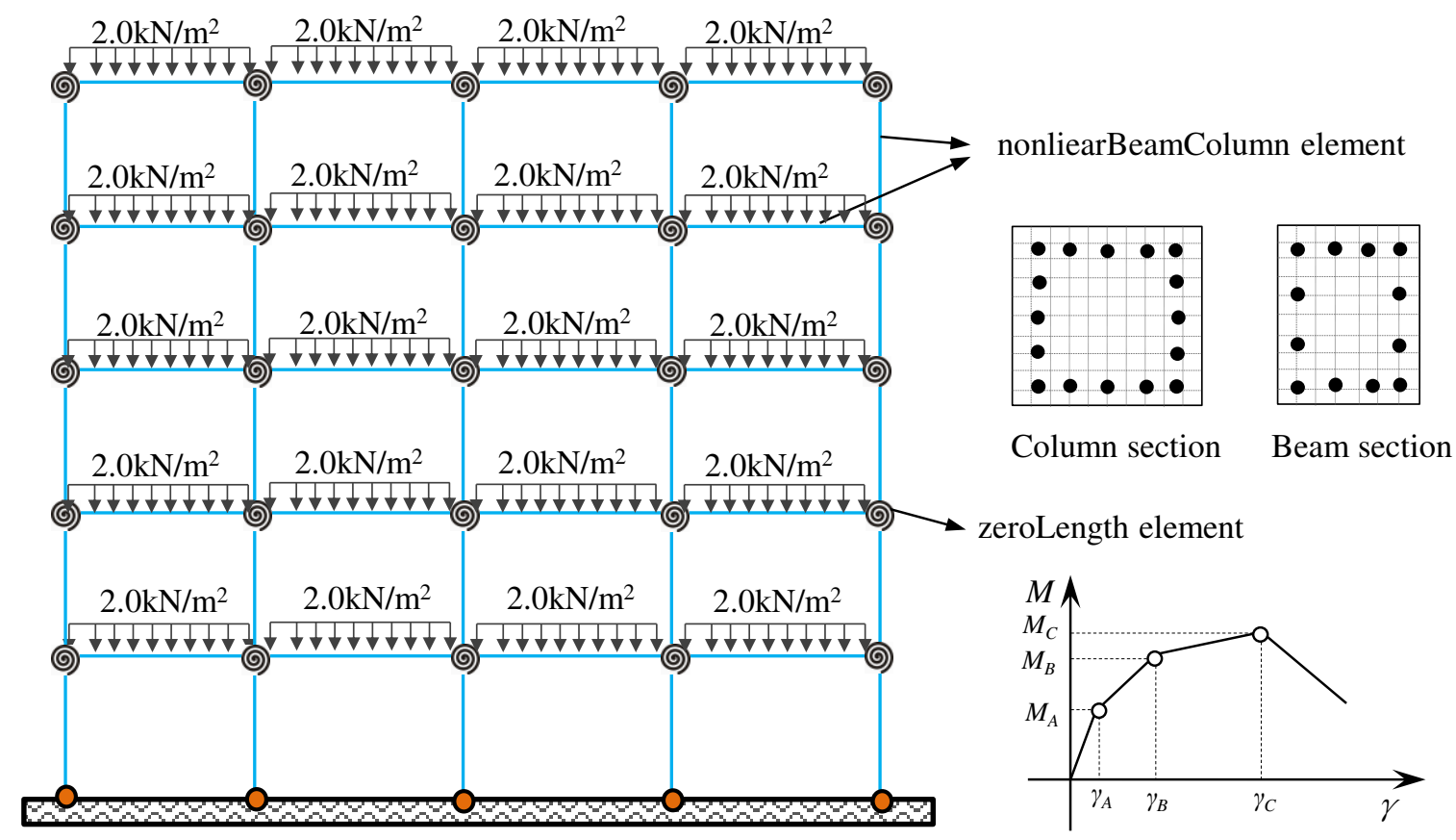

Fig.6. OpenSees element model of building frame archetype

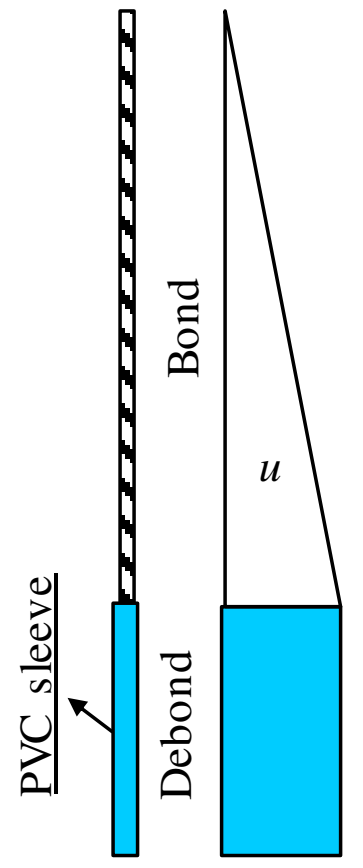

(a)
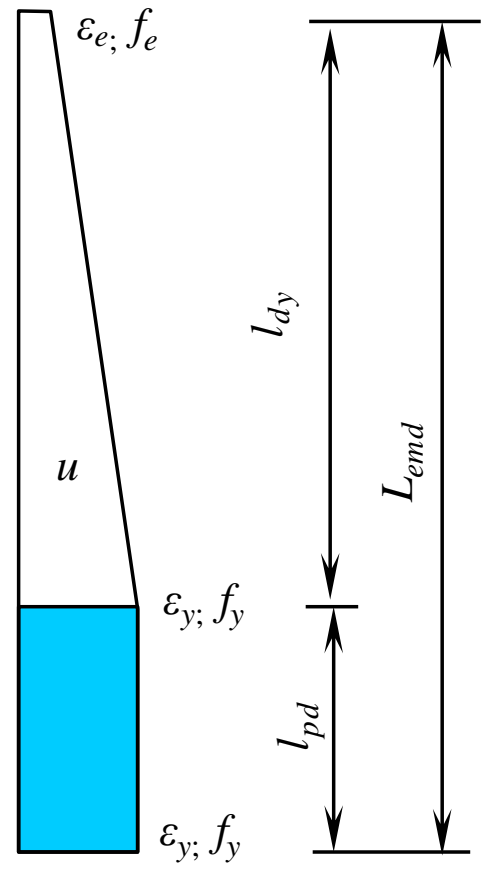

(b)

Fig. 7. Steel-bond slip considering debonding and bond effects 


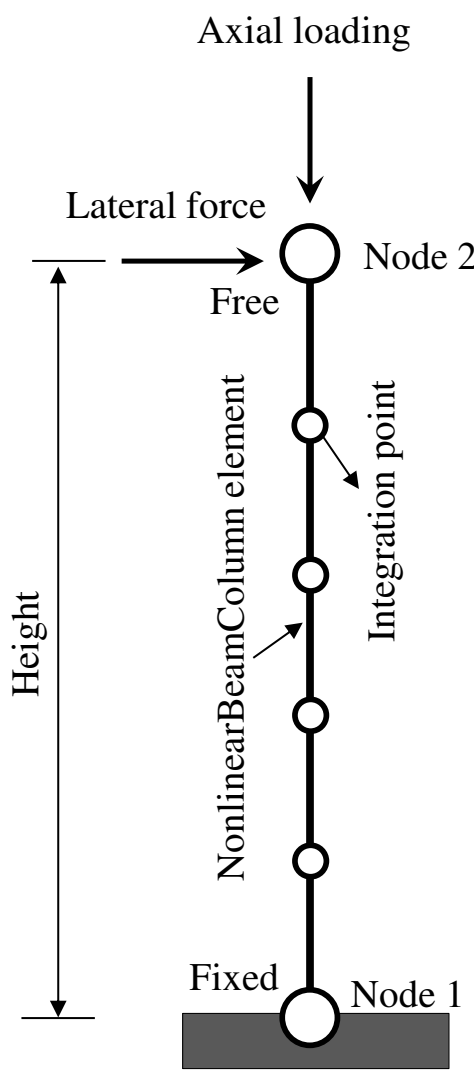

(a)

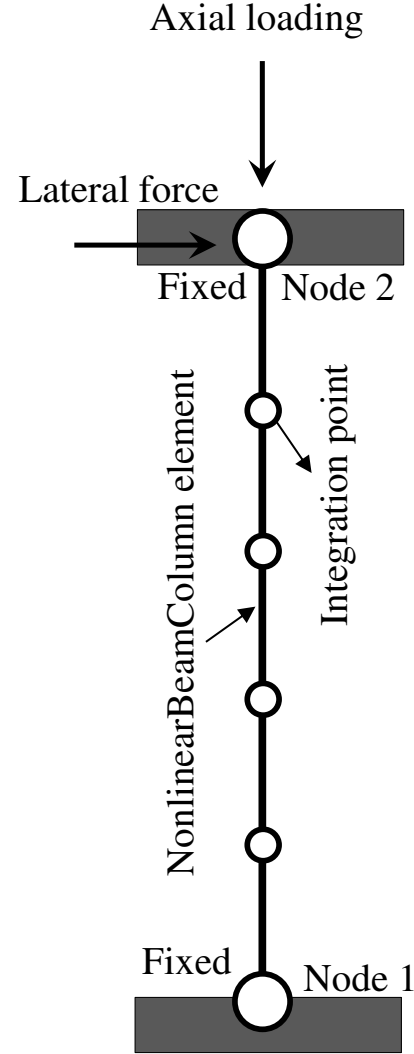

(b)

Fig.8. OpenSees element model for column: (a) cantilever; (b) double-curvature 

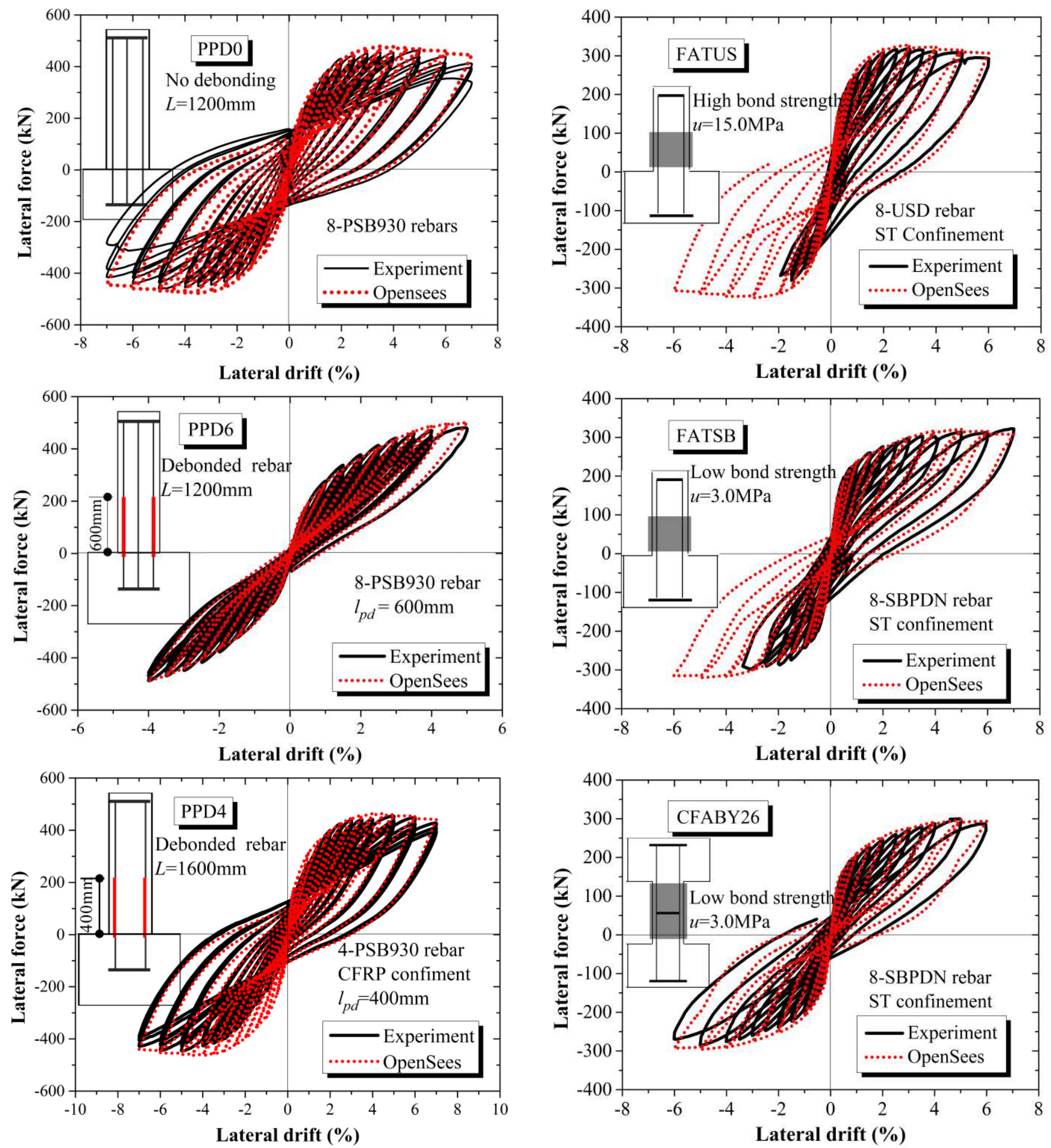

(a)

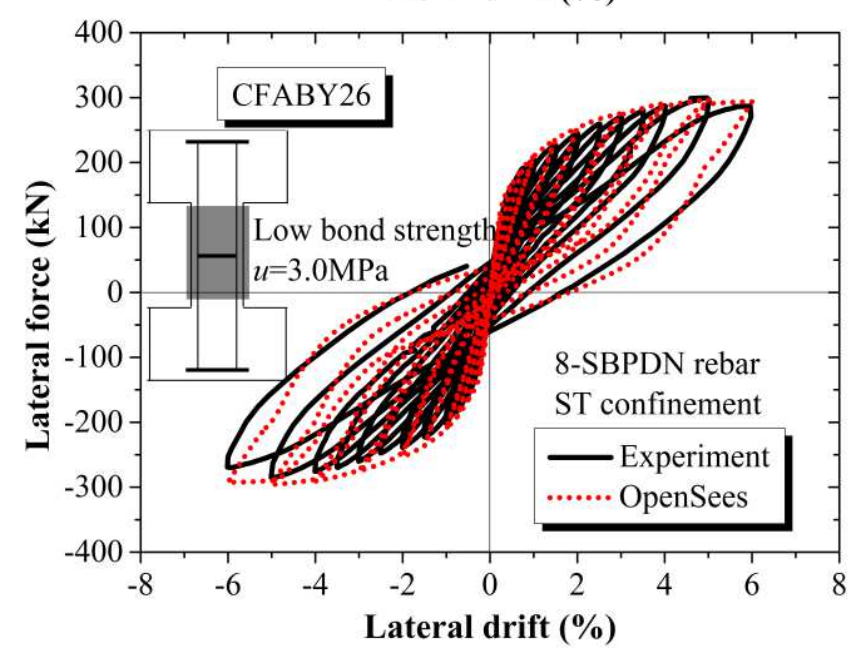

(b)

Fig. 9. Typical hysteretic curves of RC columns with LBHSRs: (a) PDHSR; (b) LBSHSR 

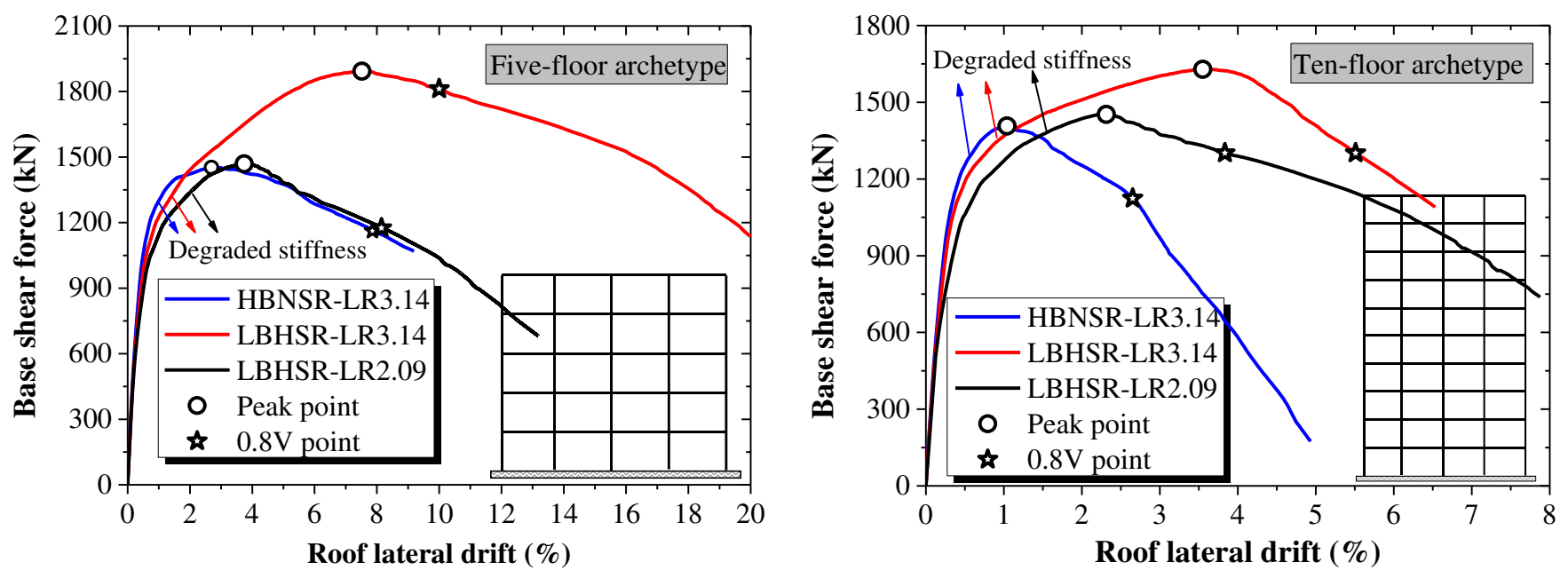

Fig.10. Pushover results of archetypes 

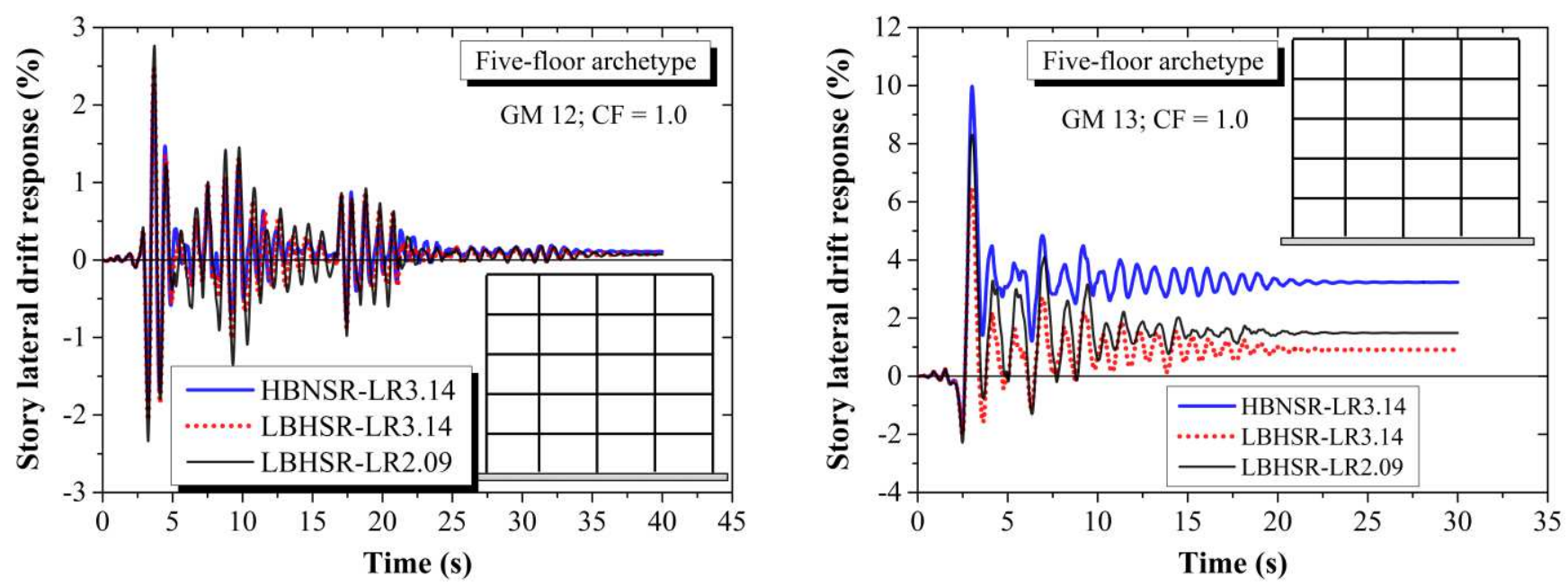

(a)
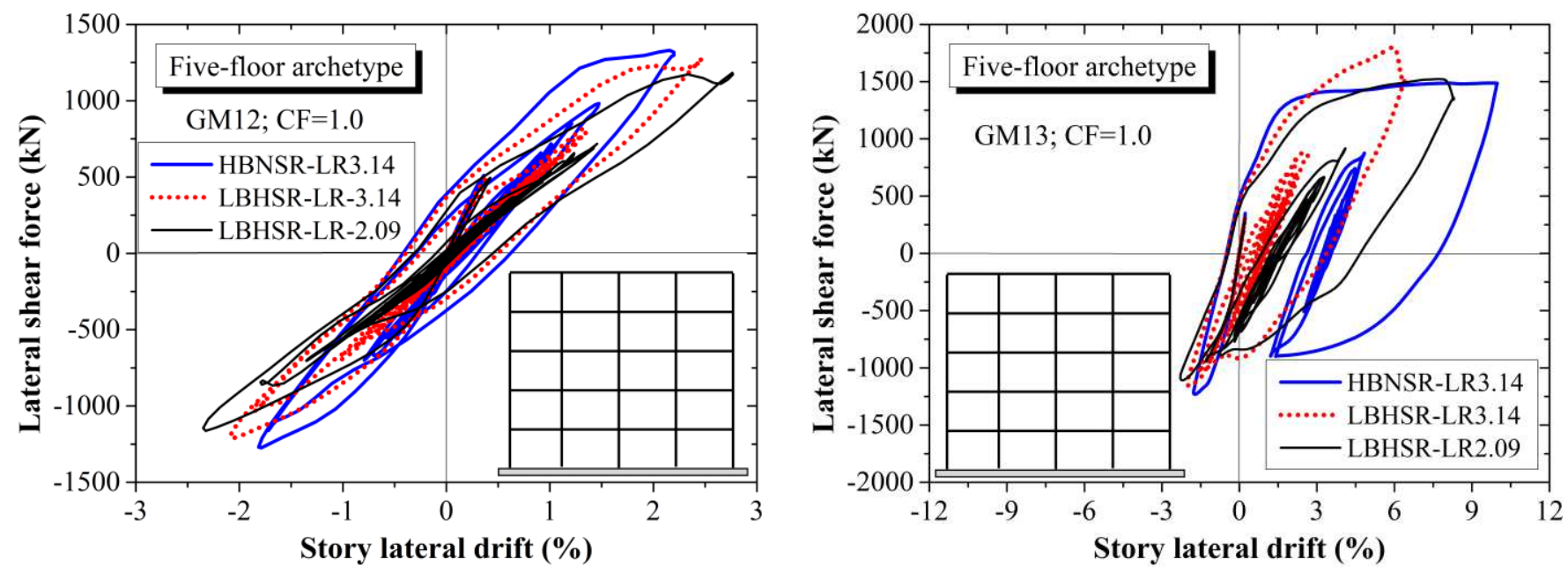

(b)

Fig.11. Dynamic responses: (a) maximum story lateral drift history-time responses; (b) hysteretic behaviors 

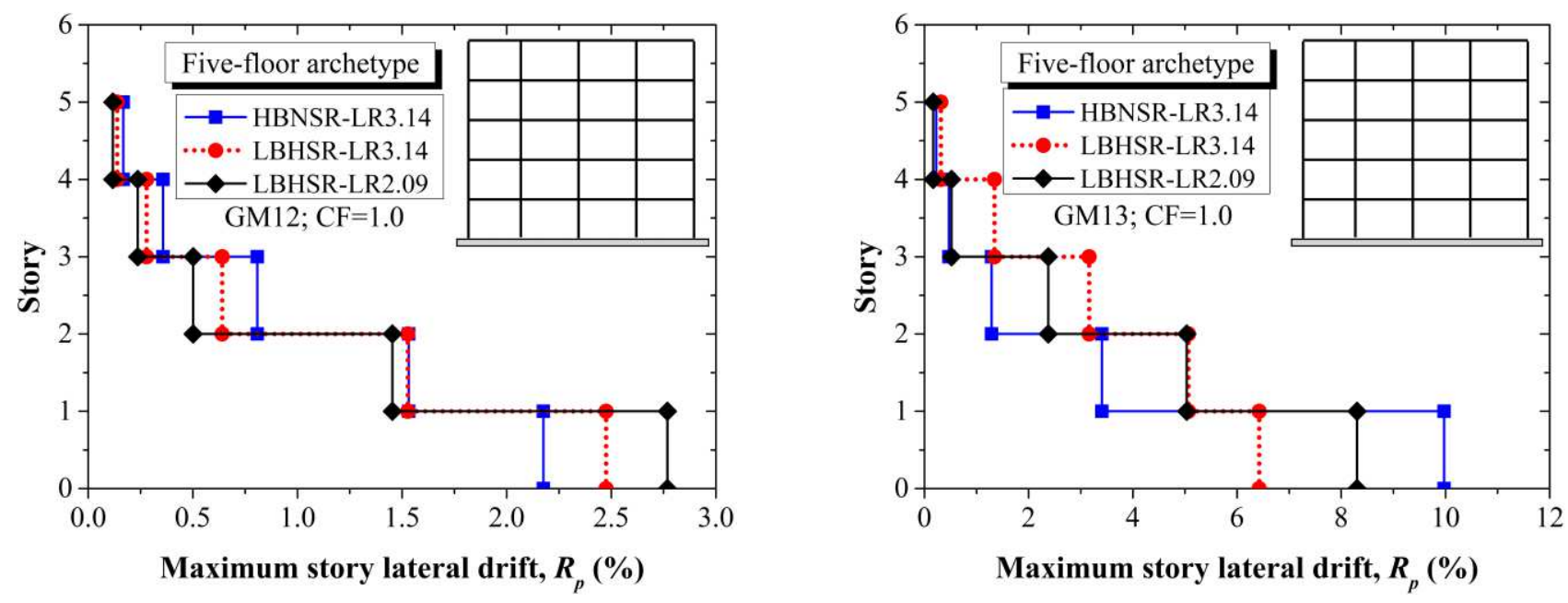

(a)
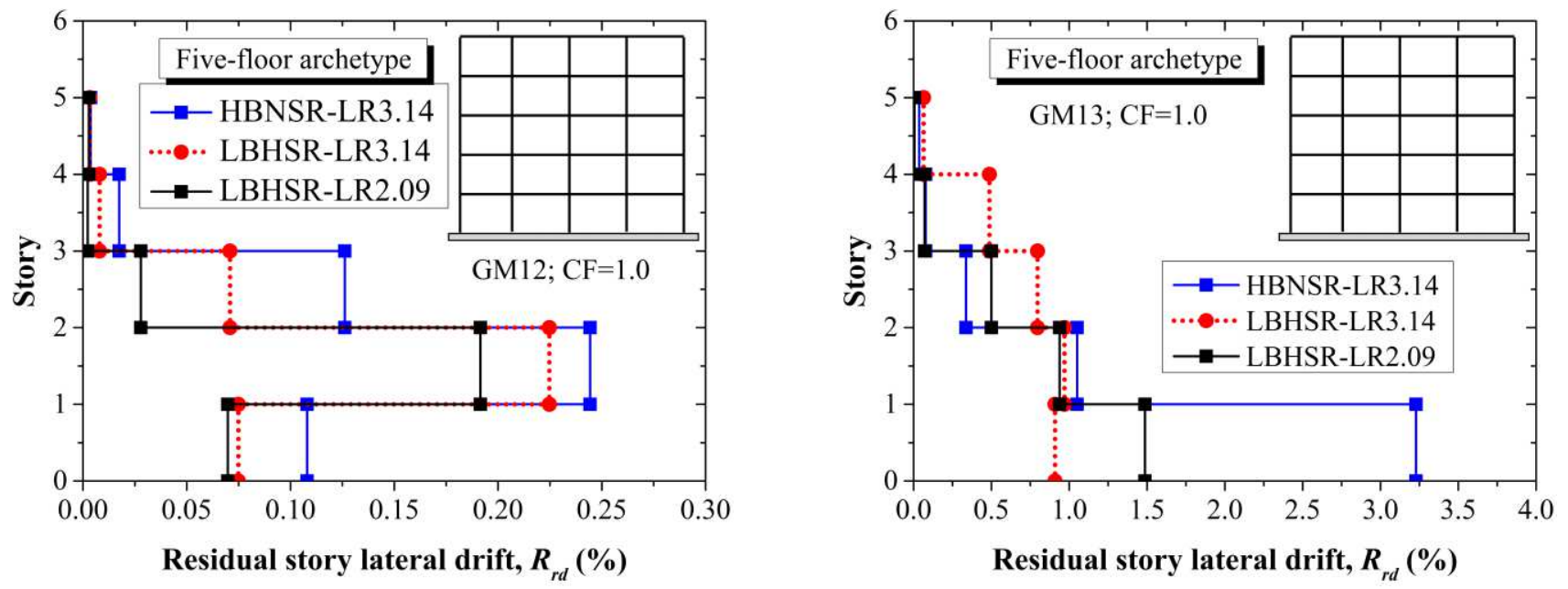

(b)

Fig.12. Lateral drift responses along with the floor: (a) maximum story lateral drift; (b) residual story lateral drift 

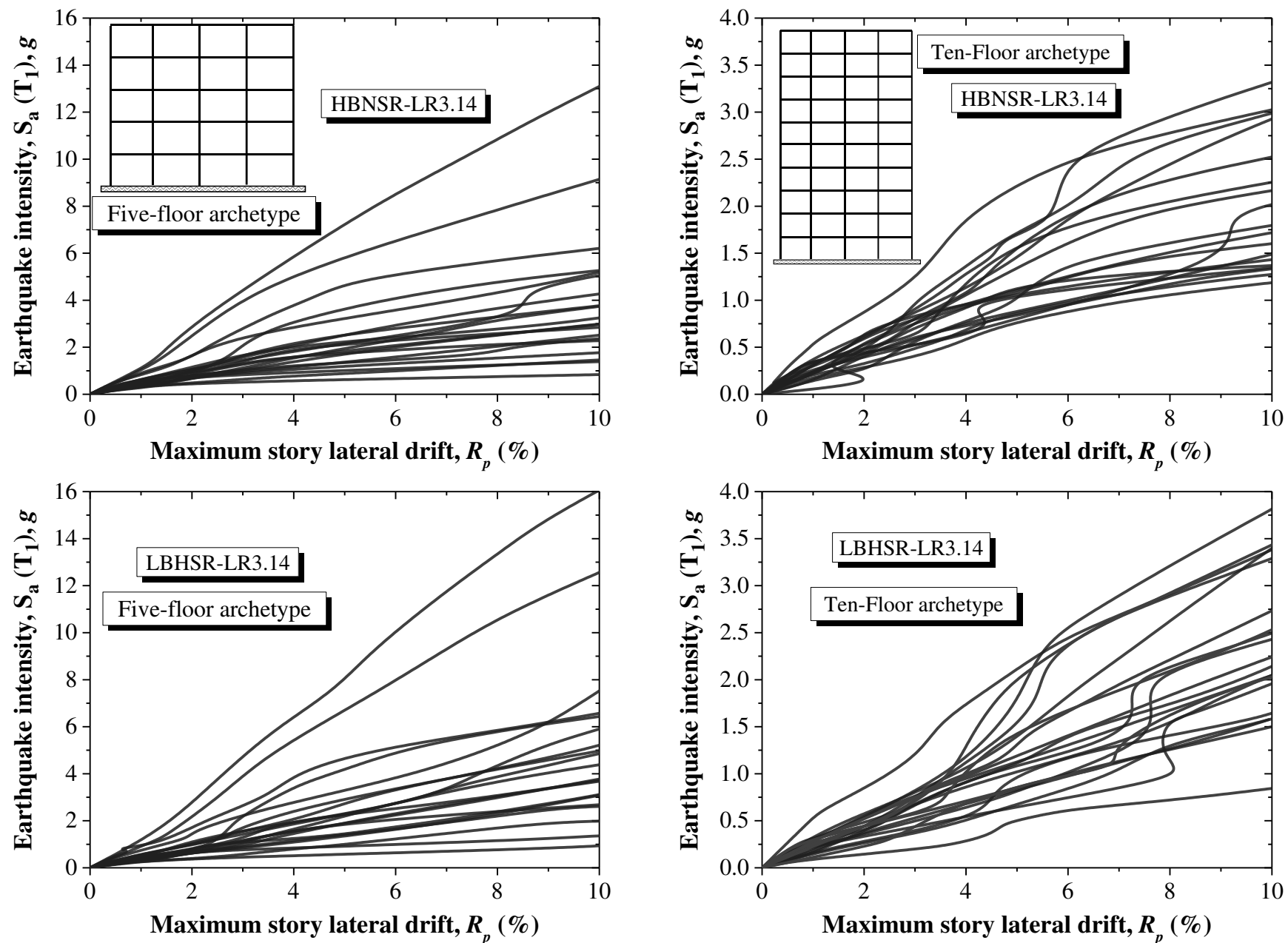

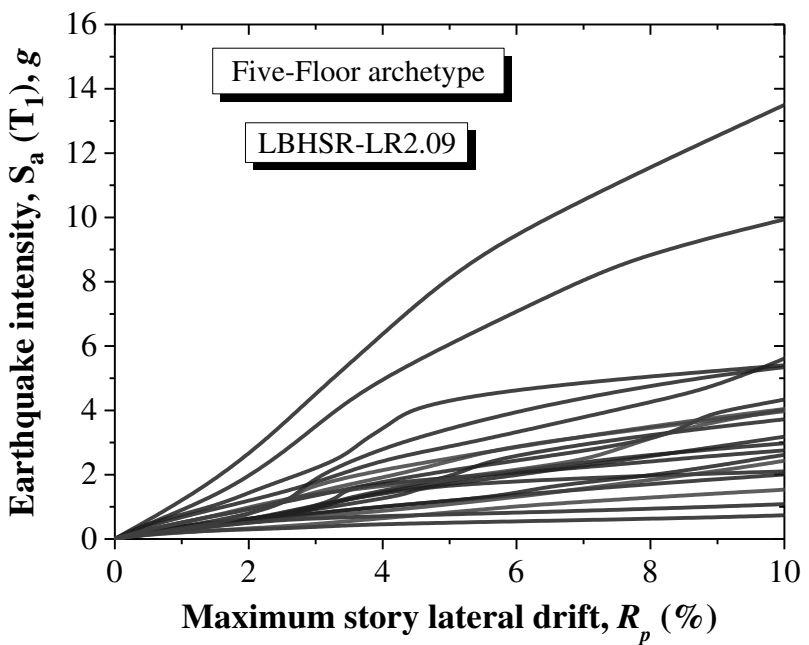

(a)

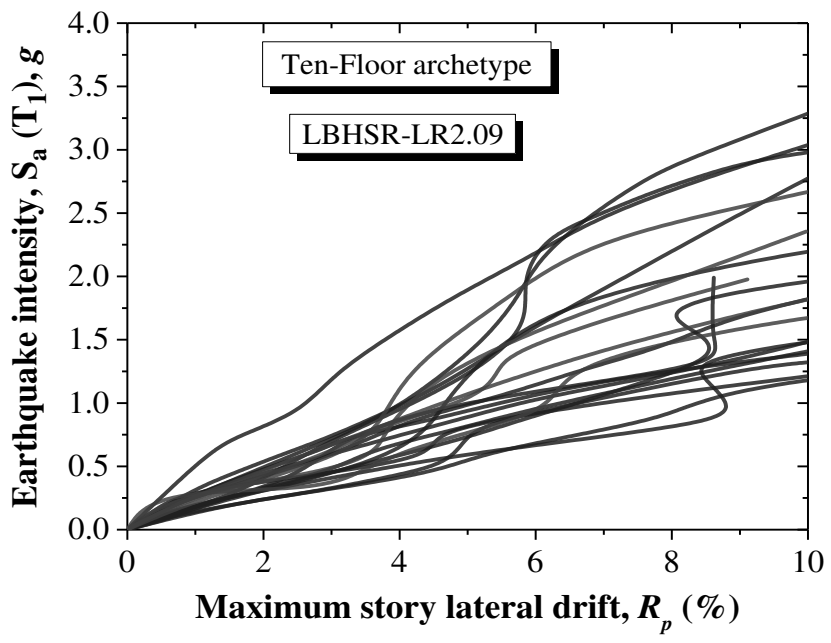

(b)

Fig.13. Relationships of earthquake intensity versus peak roof lateral drift: (a) five-floor archetype; (b) ten-floor archetype 

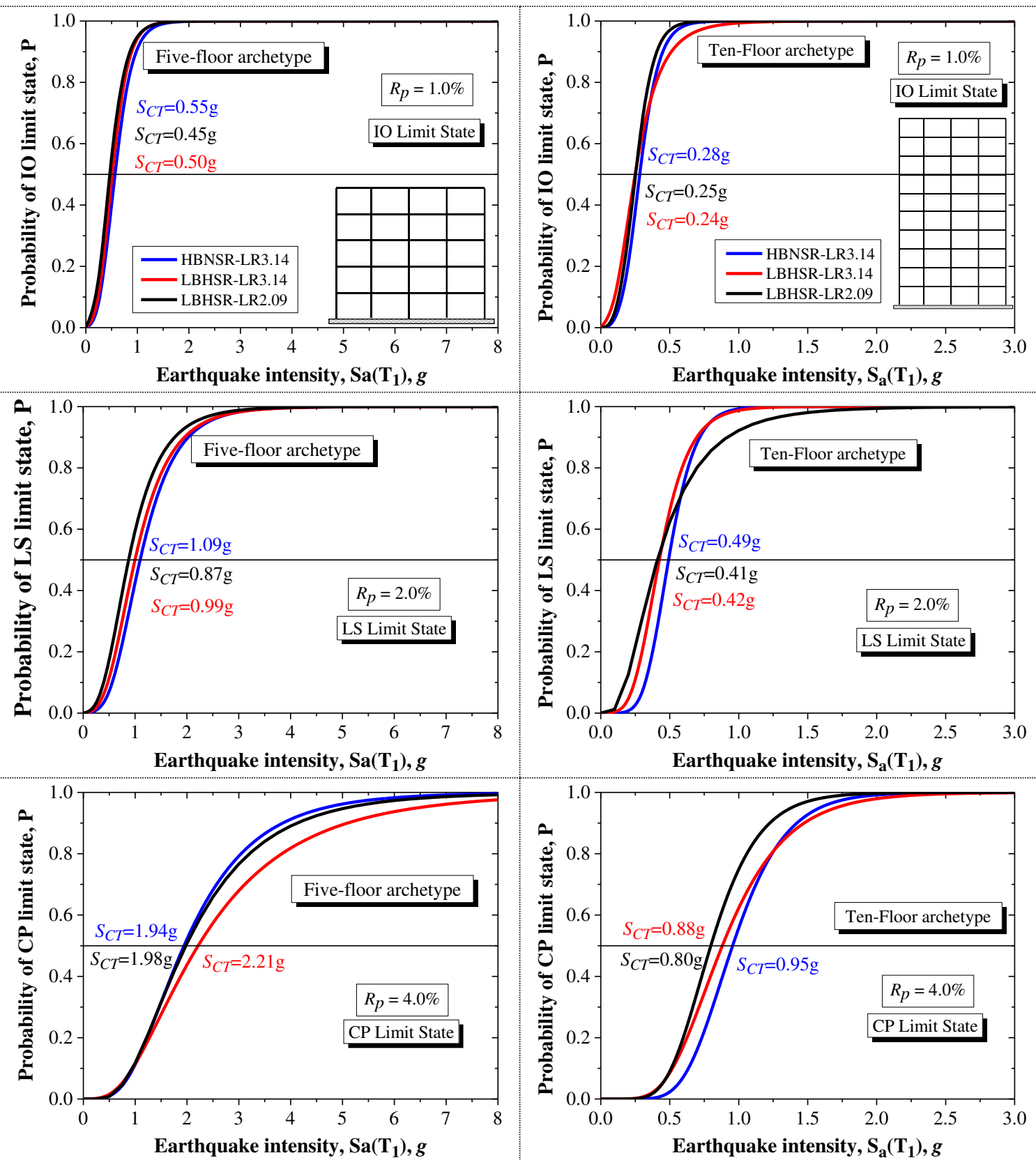

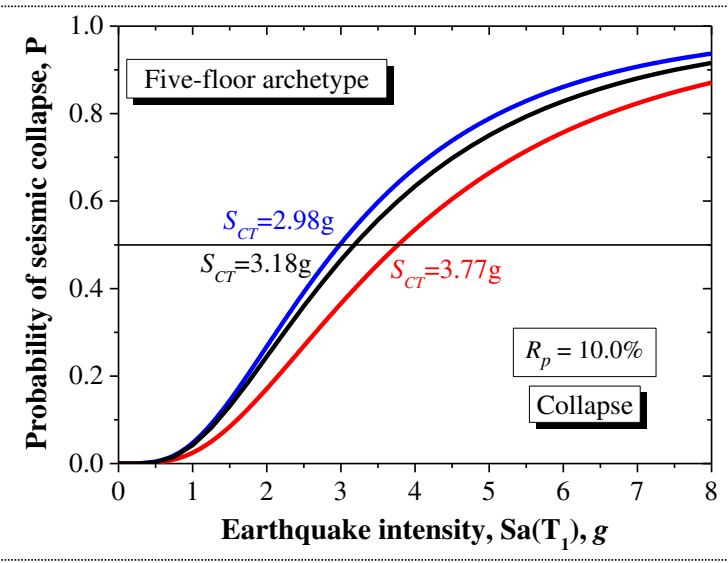

(a)

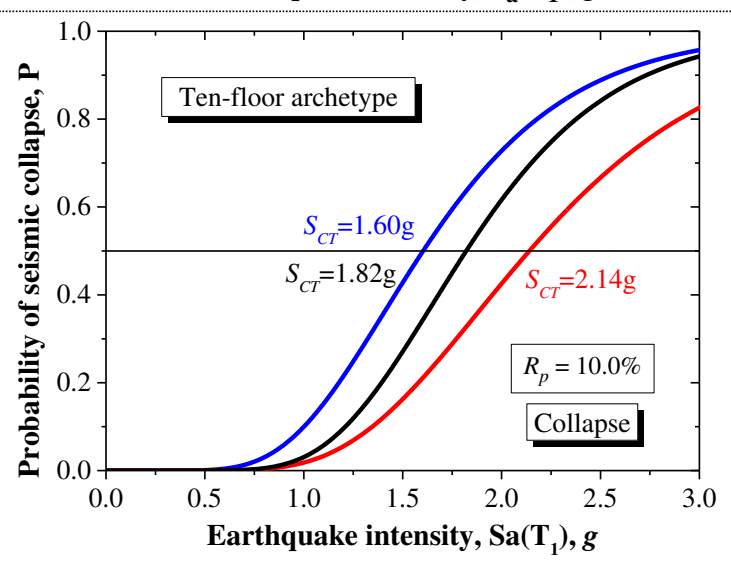

(b)

Fig.14. Seismic collapse probability of archetypes: (a) five-floor archetype; (b) ten-floor archetype 

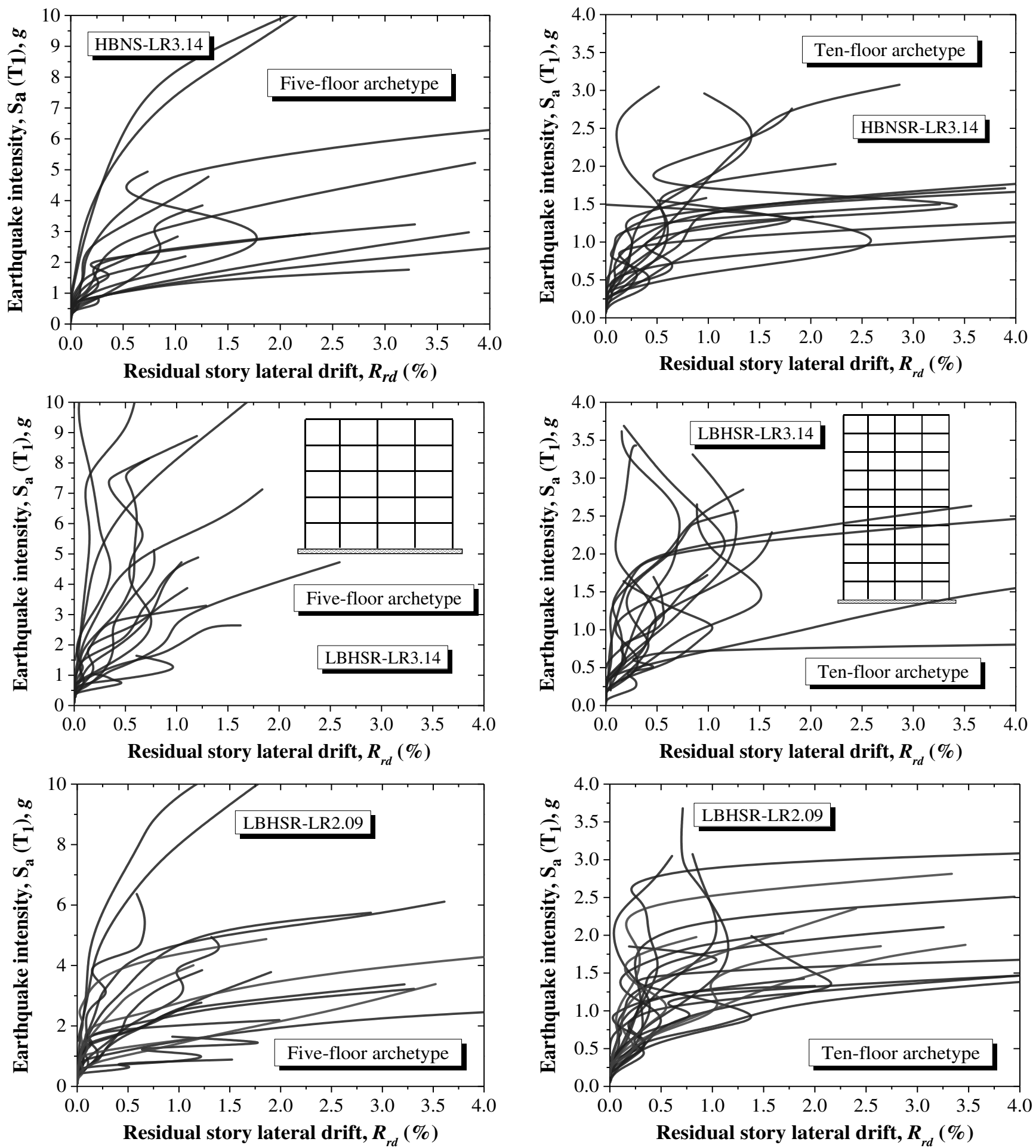

(a)

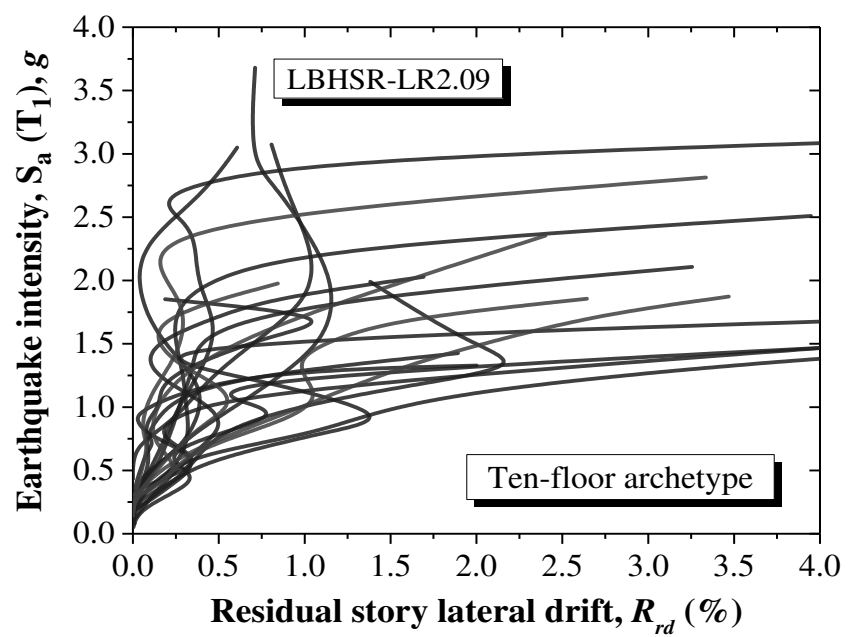

(b)

Fig.15. Relationships of earthquake intensity versus peak roof lateral drift: (a) five-floor archetype; (b) ten-floor archetype 

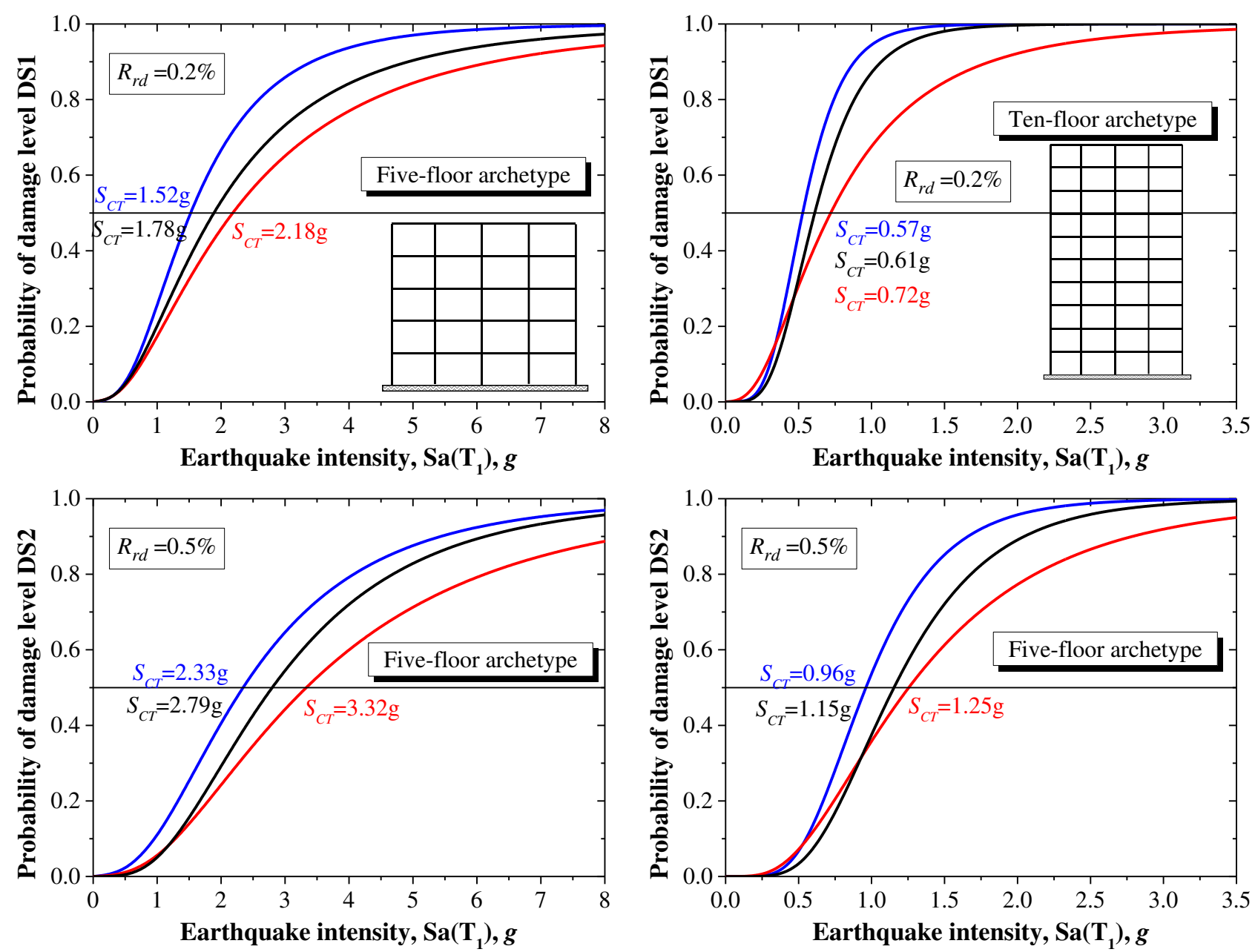

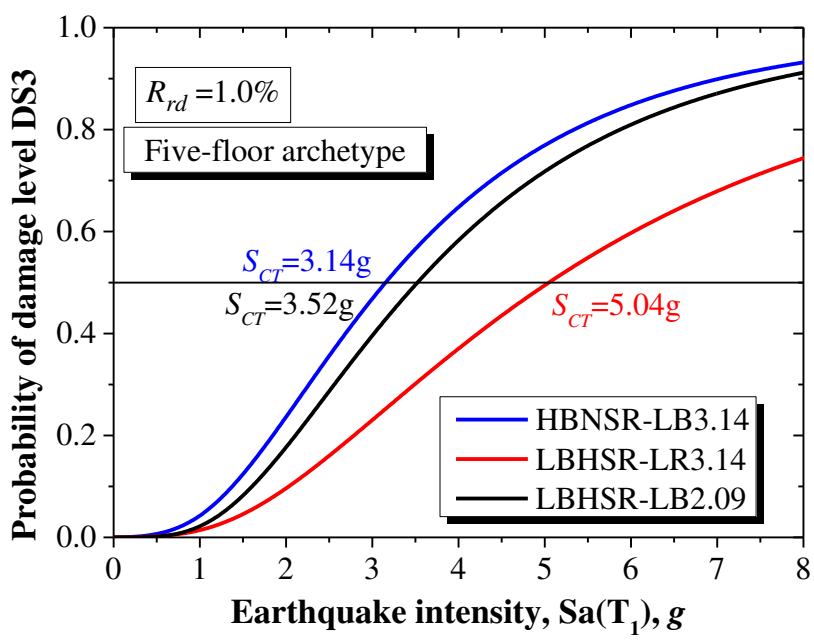

(a)

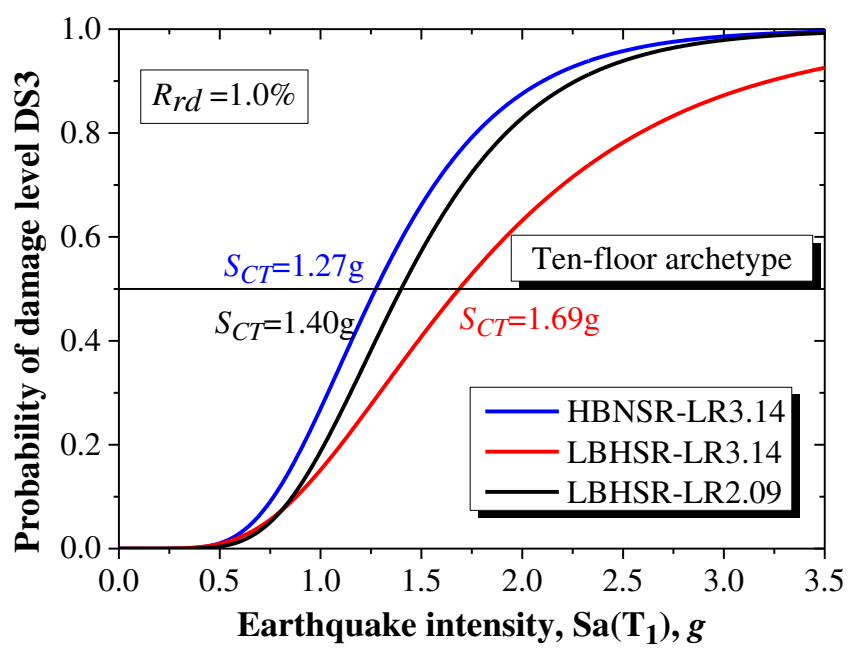

(b)

Fig.16. Seismic collapse probability of archetypes: (a) five-floor archetype; (b) ten-floor archetype 


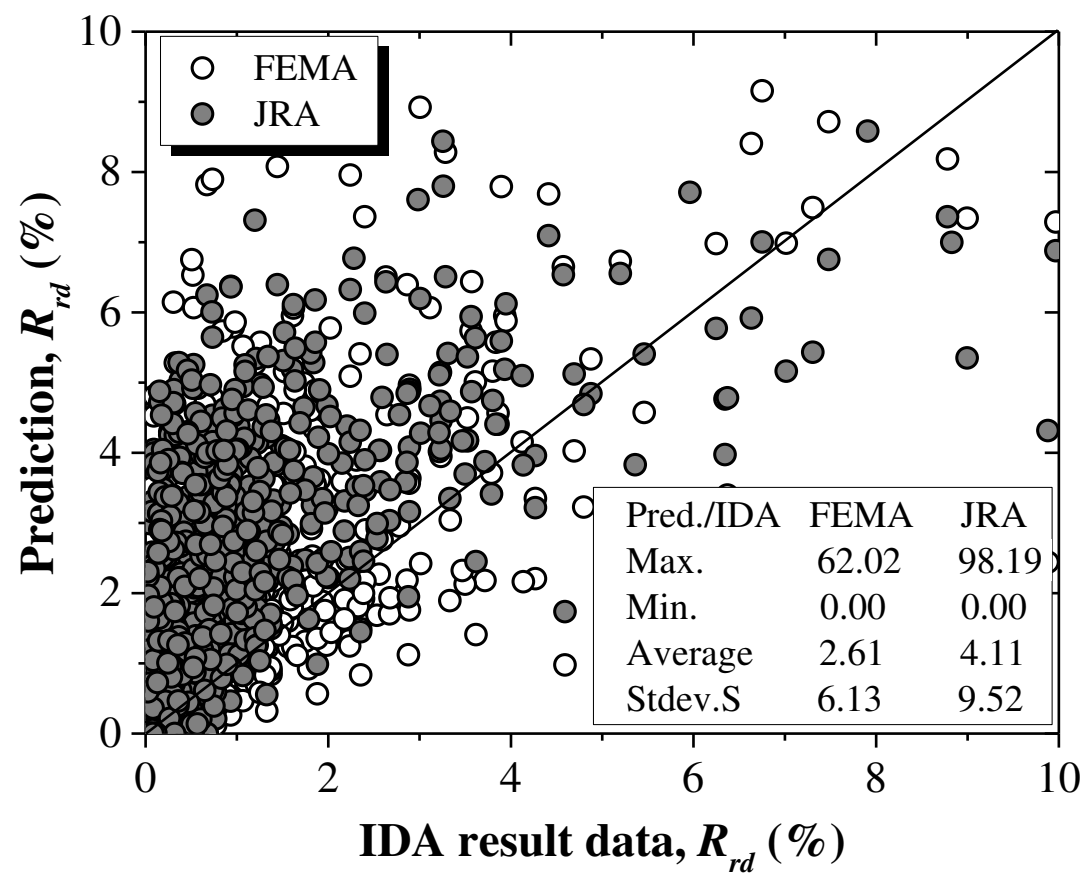

Fig.17. Comparisons of residual drifts of archetypes between prediction and IDA result data 